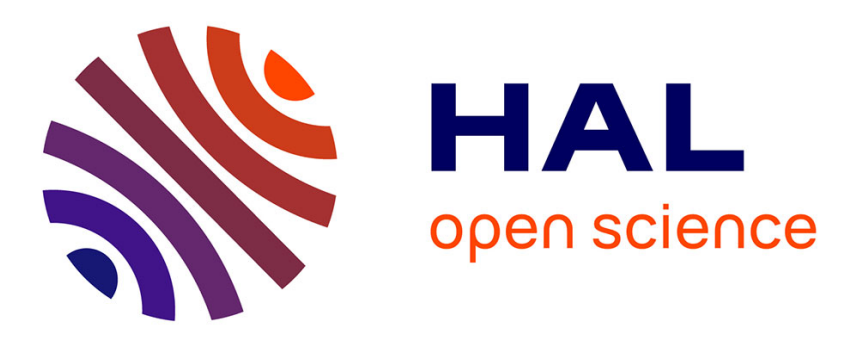

\title{
Carbon monoxide: mechanisms of action and potential clinical implications.
}

\author{
Luc Rochette, Yves Cottin, Marianne Zeller, Catherine Vergely
}

\section{To cite this version:}

Luc Rochette, Yves Cottin, Marianne Zeller, Catherine Vergely. Carbon monoxide: mechanisms of action and potential clinical implications.. Pharmacology and Therapeutics, 2013, 137 (2), pp.133-52. 10.1016/j.pharmthera.2012.09.007 . inserm-00744757

\section{HAL Id: inserm-00744757 https://www.hal.inserm.fr/inserm-00744757}

Submitted on 23 Oct 2012

HAL is a multi-disciplinary open access archive for the deposit and dissemination of scientific research documents, whether they are published or not. The documents may come from teaching and research institutions in France or abroad, or from public or private research centers.
L'archive ouverte pluridisciplinaire HAL, est destinée au dépôt et à la diffusion de documents scientifiques de niveau recherche, publiés ou non, émanant des établissements d'enseignement et de recherche français ou étrangers, des laboratoires publics ou privés. 


\section{Carbon monoxide: mechanisms of action and potential clinical implications}

Luc ROCHETTE, Yves COTTIN, Marianne ZELLER and Catherine VERGELY

Laboratoire de Physiopathologie et Pharmacologies Cardio-Métaboliques (LPPCM) INSERM UMR866 - Université de Bourgogne - Facultés de Médecine et de Pharmacie 7 boulevard Jeanne d'Arc - 21033 Dijon Cedex - FRANCE 
Small amounts of carbon monoxide (CO) are continuously produced in mammals. The intracellular levels of $\mathrm{CO}$ can increase under stressful conditions following induction of HO-1 (heme oxygnase-1), a ubiquitous enzyme responsible for the catabolism of heme. Unlike nitric oxide, which is a free radical, $\mathrm{CO}$ does not contain free electrons but may be involved in oxidative stress. Thecarbonate radical has been proposed to be a key mediator of oxidative damage resulting from peroxynitrite production, likewise, the precursor of the carbonate radical anion being bicarbonate and carbon dioxide. We report herein some of the transcription factors and protein kinases involved in the regulation of vascular $\mathrm{HO}-1$ expression. Beyond its widely feared toxicity, $\mathrm{CO}$ has revealed a very important biological activity as a signaling molecule with marked protective actions namely against apoptosis and endothelial oxidative damage. Abnormal metabolism and function of $\mathrm{CO}$ contributes to the pathogenesis and development of cardiovascular diseases. Important results have been reported in which $\mathrm{CO}$ and CO-releasing molecules (CO-RMs) prevent intimal hyperplasia by arresting hyperproliferative vascular smooth muscle cells and increased mobilization and recruitment of bone-narrow-derived progenitor cells. Clinical studies have demonstrated beneficial properties of CO-RMs in transplantation. The anti-inflammatory properties of $\mathrm{CO}$ and CO-RMs have been demonstrated in a multitude of animal models of inflammation, suggesting a possible therapeutic application for inflammatory diseases. The development of a technology concerning CO-RMs that controls the delivery and action of CO under different pathological conditions represents a major step forward in the development of CO-based pharmaceuticals with therapeutic applications.

Keywords: carbon monoxide. carbonate radical. transcription factors. CO-releasing molecules. CO-RMs. 


\section{Abbreviations}

AP-1, activator protein-1; ARE, antioxidant response element; $\mathrm{BH}_{4}$, tetrahydrobiopterin; Cavs, caveolins; $\mathrm{CO}$, carbon monoxide; $\mathrm{CO}-\mathrm{RMs}$, CO-releasing molecules; $\mathrm{CO}_{3}{ }^{\circ}$, carbonate radical; cGMP,cyclic 3':5'-guanosine monophosphate; DDAH; dimethylarginine dimethylaminohydrolase; $\mathrm{HO}-1$, eCO, exhaled CO; EETs, epoxyeicosatrienoic acids; heme oxygnase-1, $\mathrm{H}_{2} \mathrm{~S}$, hydrogen disulfide; Hb, hemoglobin; LDA, Lipid Derived Aldehydes; LPC, Iysophosphatidylcholine; MAPKs, mitogen-activated protein kinases;MSCs, multipotent marrow stromal stem cell; NF-KB, nuclear factor- $\mathrm{\kappa B} ; \mathrm{NO}$, nitric oxide; $\mathrm{NO}_{2}-\mathrm{FAS}$, nitro-fatty acid derivates; NRF1, nuclear respiratory factor 1;Nrf2, nuclear factor E2-related factor 2; ONOO-, peroxynitrite; PKG, protein kinase-G; PRMTs, protein arginine methyltransferases; RNS, reactive nitrogen species; ROS, reactive oxygen species; SOD, superoxide dismutase; sGC, guanylate cyclase; StRE, stressresponse elements 


\section{Contents}

1- Introduction

2- Endogenous production of $\mathrm{CO}$

3- Overview: catabolism of endogenous CO

4- Heme-oxygenase and cellular targets of $\mathrm{CO}$

5- $\quad \mathrm{CO}$, interactions with endogenous compounds and functions

6- $\quad$ Signaling to heme-oxygenase and CO

7- Dysregulation, disease and potential therapeutic use of CO and CO-RMs

8- Summary and future direction

References 


\section{1- Introduction}

The diverse physiological actions of "biological gases": dioxygen $\left(\mathrm{O}_{2}\right)$, hydrogen disulfide $\left(\mathrm{H}_{2} \mathrm{~S}\right)$, nitric oxide (NO) and carbon monoxide (CO) have attracted much interest(Lamon, et al., 2009; Motterlini \& Otterbein, 2010; Rochette \& Vergely, 2008b; Ryter \& Otterbein, 2004; R. Wang, 2002; L. Wu \& Wang, 2005). The multiplicity of gas actions and gas targets associated with the difficulty in measuring local gas concentrations obscure detailed mechanisms whereby gases exert their actions. A central question is how do these gases interact with one another when transducing signals and modulating cell function? Among the major free radicals with essential functions in cells are reactive oxygen species (ROS) like superoxide anion $\left(\mathrm{O}_{2}{ }^{-}\right)$, hydroxyl radical $\left({ }^{\circ} \mathrm{OH}\right)$ and reactive nitrogen species (RNS) such as nitric oxide ( ${ }^{\circ} \mathrm{NO}$ ) (Halliwell, 2007a). It has brought into focus reactive species described by chemists but forgotten in biology. About $0.3 \%$ of $\mathrm{O}_{2}{ }^{--}$present in cell cytosol exists in its protonated form: hydroperoxyl radical $\left(\mathrm{HO}_{2}{ }^{\circ}\right)$. Water $\left(\mathrm{H}_{2} \mathrm{O}\right)$ can be split into two free radicals: ${ }^{\bullet} \mathrm{OH}$ and hydrogen radical $\left(\mathrm{H}^{\circ}\right)$. The transmembrane electrochemical potential is a major force in cellular energy production.Several free radicals, including thiyl radicals (RS $\left.{ }^{\circ}\right)$ and nitrogen dioxide $\left(\mathrm{NO}_{2}{ }^{\circ}\right)$ are known to isomerize double bonds. Evidence is emerging that hydrogen sulphide $\left(\mathrm{H}_{2} \mathrm{~S}\right)$, essentially as hydrogen thiol $(\mathrm{H}-\mathrm{SH})$, is a signaling molecule in vivo which can be a source of free radicals(Rochette \& Vergely, 2008a). The Cu-Zn superoxide dismutase (SOD) enzyme can oxidize the ionized form of $\mathrm{H}_{2} \mathrm{~S}$ to hydro-sulphide radical: $\mathrm{HS}^{\circ}$. Recent studies suggest that $\mathrm{H}_{2} \mathrm{~S}$ plays an important function in cardiovascular functions (Rochette \& Vergely, 2008b; Whiteman \& Moore, 2009). Unlike the high reactivity of NO which is a free radical, $\mathrm{CO}$ does not contain free electrons. It has been reported that in the cell carbonate radical anion $\left(\mathrm{CO}_{3}{ }^{-}\right)$may be formed after the oxidation of $\mathrm{CO}$ to $\mathrm{CO}_{2}$ (Kajimura, Fukuda, Bateman, Yamamoto, \& Suematsu, 2010). In this review, we will describe some functions of this radical such as its participation in the activity of Cu-Zn SOD. Carbonate radicals can be also formed when ${ }^{\circ} \mathrm{OH}$ reacts with carbonate or bicarbonate ions. Recently, it has been reported that carbonate anion were potentially relevant oxidant in physiological environments. In this article, we will develop the importance of CO, its interaction with free radicals and the potential medical applications of this gas molecule; two organs beingparticularly susceptible to $\mathrm{CO}$ : the heart and the brain. Our focus is on the 
cardiovascular effects of CO and CO-RMs(Motterlini \& Otterbein, 2010; Prockop \& Chichkova, 2007). In this regard, we discuss in a next part of this review whyCO is an important signaling mediator possessing vasodilatory properties, which are achieved by activation of the guanylate-cyclase-cGMP pathway as well as large-conductance potassium channels(Dong, et al., 2007; Wilkinson \& Kemp, 2011).

\section{2- Endogenous production of carbon monoxide}

\subsection{Production of $\mathrm{CO}$ and "gas-sensors"}

$\mathrm{CO}$ is a ubiquitous air pollutant. It originates from the oxidation or combustion of organic matter, coke and tobacco. Cigarette smoke accounts for a major source of CO exposure in humans.Clinical sign of $\mathrm{CO}$ poisoning include shortness of breath and headache. Lethality after $\mathrm{CO}$ exposure results from tissue hypoxia following hemoglobin saturation. CO diminishes the blood capacity to deliver oxygen to tissue leading to hypoxia(L. Wu \& Wang, 2005). Small amounts of carbon monoxide (CO) are continuously produced in mammals. The production rate of $\mathrm{CO}$ is $20 \mathrm{micromol} / \mathrm{h}$ in the human body. A meta-analysis based on 15 studies in 632 asthmatics and 734 healthy subjects demonstrates that exhaled CO (eCO)was increased in both adults and children with asthma, irrespective of steroid treatment, disease severity or level of asthma control(J. Zhang, et al., 2010). Recently, it has been reported in preschool-aged children, that eCO levels in those with asthma attacks were significantly higher as these in healthy children. eCO levels during asthma attacks significantly decreased after inhalation therapy with a combination of a $\beta 2$-agonist and sodium cromoglycate (Ohara, et al., 2012). Apart from asthma, other diseases such as allergic rhinitis, bronchiectasis, lower and upper respiratory tract infections, interstitial lung disease and cystic fibrosis have also shown an increased production of eCO. eCO was even found to be elevated in asymptomatic atopic subjects. Two groups of subjects were studied: non-atopic control subjects and asymptomatic individuals. Levels of eCO were elevated compared with these in healthy subjects (Horvath \& Barnes, 1999). These findings suggest that increased eCO level may be an indicator of airway inflammation but it does not discriminate between diseases. 
To understand how gases such as CO are functioning in physiological processes, it is important to know how much gas is producedanddelivered to a given target. Four major determinants of the effective gas concentration are (a) the membrane permeability of the gas (b) the physiochemical properties of the gas itself; (c) the properties of the local environment, including the surrounding media through which a gas travels including physico-chemistry properties of the tissueand (d) scavenging systems, including chemical reactions that consume the gas(Kajimura, et al., 2010). Control of intracellular heme levels was previously thought to occur through a balance among its mitochondrial biosynthesis, utilization by hemoproteins, and catabolism by heme oxygenases ( $\mathrm{HO}$ ). Both cell surface and organelle-associated heme transporters are likely involved in the sequestering and trafficking of intracellular heme.Heme also binds $\mathrm{NO}, \mathrm{CO}$ and $\mathrm{O}_{2}$, allowing hemoproteins to serve as gas sensors and signal transducers(Khan \& Quigley, 2011).

Therefore,heme based sensor proteins are key regulators of cellular responses to changes in $\mathrm{O}_{2}, \mathrm{CO}, \mathrm{NO}$, and $\mathrm{H}_{2} \mathrm{~S}$ levels. These gas sensors act as signal transducers by coupling a "regulatory" heme binding site to a "functional" signal-transmitter site. Both CO and NO are strongheme-ligands, NO has a much higher affinity for ferrous heme (nitrosylhemoglobine) than does CO (Lecour, Maupoil, Siri, Tabard, \& Rochette, 1999; Lecour, et al., 2001; C. Vergely, Maupoil, Clermont, Bril, \& Rochette, 2003).

\subsection{Importance of Heme oxygenases}

In addition to uptake of exogenous gas, cells and tissues produce significant amounts of $\mathrm{CO}$ as an elimination product of cellular metabolism, largely from heme degradation catalyzed by microsomal heme oxygenases (HO; E.C. 1:14:99:3). Heme serves as a vital cofactor in oxygen transport proteins (hemoglobin, myoglobin) and in enzymes involved in critical cellular processes such as respiration, inflammation or drug metabolism. Hemo-protein turnover leads to the production of $\mathrm{CO}$ as a necessary consequence of heme utilization. Conversely, the physiological effects of CO depend on its ability to form complexes with the heme moieties of cellular hemo-proteins. The substrate is ferric protoporphyrin IX and the other products of the reaction are ferrous iron (which will lead to an equivalent of ferric iron and superoxide) and biliverdin (Figure 1). $\mathrm{NADPH}, \mathrm{O}_{2}$, and flavoprotein reductases 
(cytochrome P450 reductase) are also required for turnover of HO.It is now well recognized that HO-mediated heme degradation has multiple roles in mammals, including antioxidant and iron reutilization functions.

Threeisoforms of $\mathrm{HO}$ have been characterized: an inducible form (HO-1) that is up-regulated, especially in the spleen and liver, in response to various types of stress, and two constitutive forms (HO-2 and HO-3).HO-1 and HO-2 represent the products of distinct genes (ho-1, ho-2, also specified as hmox1, $h$ mox2).The inducible form of heme oxygenase, HO-1, occurs at a high level of expression in the spleen and other tissues that degrade senescent red blood cells, including specialized reticulo-endothelial cells of the liver and bone marrow. High levels of $\mathrm{HO}$ activity are detected in these tissues. $\mathrm{HO}$ is present in hematopoietic stem cells of the bone marrow(Abraham, Nelson, Ahmed, Konwalinka, \& Levere, 1989). HO-2 is expressed throughout the brain, in nerves innervating smooth muscle, and, likely, in all other tissues at low levels. HO-2 does not appear to be induced, and free heme is the limiting factor of CO production(Morse, Lin, Choi, \& Ryter, 2009).HO-1 belongs to a larger family of stress proteins whose transcriptional regulation also responds to adverse environmental conditions. Although HO-1 plays an essential role in the degradation of $\mathrm{Hb}$-derived heme, it is also a stress protein known as heat-shock protein-32 (HSP32). The ho-1gene, which encodes a low-molecular-weight stress protein (32 kDa in humans and rats, $34 \mathrm{kDa}$ in mice), provides a model system for the study of redox-regulated gene expression in mammalian systems.Generally, HO-1 is thought to play a cytoprotective role against oxidant insults. As the liver plays a crucial role for the body's iron homeostasis (eg. via secretion of the iron regulatory hormone hepcidin) and also for systemic inflammation, hepatic HO-1 may be important for the regulation of both systems. In particular, cell-specific functions of HO-1 in liver tissue macrophages (Kupffer cells) might be of major significance, because these cells play a key role in iron recycling and also in the control of hepatic and systemic inflammatory responses(Immenschuh, Baumgart-Vogt, \& Mueller, 2010).Within the normal liver, HO-2 is constitutively expressed within hepatocytes, Kupffer cells, endothelial cells and Ito cells.

The function of HO-3 remains unclear, but it has been cloned from rat brain, suggesting a neural function. This enzyme is structurally similar to $\mathrm{HO}-2$, but is less efficient at degrading heme. One theory suggests that HO-3 may be derived from retrotransposition of HO-2 gene since HO-3 gene does not contain introns(Scapagnini, et al., 2002). 
HO-1 in mesangial and endothelial cells interacts with caveolins (Cavs), structural proteins in caveolae beside membrane (lipid) rafts.Cav-1 and Cav-2 localizes in caveolae in a manner regulated by various agents; HO-1 is negatively regulated by Cav-1(Patel \& Insel, 2009). In vascular smooth muscle cells, loss of Cav-1 or HO-1 leads to increased neointimal formation and $\mathrm{CO}$ promotes antiproliferative effects through Cav-1, specifically its ability to activate p38 mitogen-activated protein kinase(H. P. Kim, et al., 2005).

In humans, as we previously noted,endogenous $\mathrm{CO}$ arises principally from the action of microsomal $\mathrm{HO}$, which catalyze the rate-limiting step in heme degradation. The HO reaction generates one molecule of CO per molecule of oxidized heme. For every mole of CO formed by the mechanism, one mole of ferrous iron is released, and one mole of the linear tetrapyrrole biliverdin-IX alpha is produced. The latter undergoes further metabolism to bilirubin-IXa by $\mathrm{NAD}(\mathrm{P}) \mathrm{H}$ : biliverdin reductase. The $\mathrm{HO}$ enzymes play an important physiological role in hemoglobin turnover in reticulo-endothelial tissues such as the spleen, kidney and liver where senescent erythrocytes are destroyed(Ryter \& Otterbein, 2004). Finally, the important point in vivo is that the intracellular levels of $\mathrm{CO}$ can markedly increase under stressful conditions following induction of HO-1. Activation of HO-1 pathway is part of a complex homoeostatic adaptation of cells to the redox imbalance inflicted by stressful stimuli, and it is becoming evident that increased $\mathrm{CO}$ production reflects a dynamic and active involvement of this by-product in the cytoprotective response. In closing this section, we should note that there have been reports suggesting that $\mathrm{HO}-1$ induction could be harmful to the cell under certain circumstances;in particular, the release of heme-chelated ferrous iron that could potentially interact with $\mathrm{H}_{2} \mathrm{O}_{2}$, producing the highly toxic hydroxide radical. The causative factor in the etiology of a variety of disease states is the presence of iron-ROS, which can result in cell damage or which can affect the signaling pathways involved in cellular dysfunctions(Benderitter, et al., 1996; Heli, Mirtorabi, \& Karimian, 2011; Rochette, et al., 2011).

The antioxidant protection afforded by HO-1 activity cannot be explained alone by the conversion of heme in exchange for increased intracellular iron, which is potentially toxic. This antioxidant protection of HO-1 with respect to iron metabolism is possible by further coupling with proteins that promote either the sequestration or the export of the liberated iron. HO-1 has been associated with iron efflux pathways promotingthe synthesis of ferritin, 
which secondarily neutralizes reactive iron.Thus ferritin seems to confer cytoprotectionagainst oxidative challenge and potentially plays an intermediate role in $\mathrm{HO}$ mediated anti-apoptotic protection(Berberat, et al., 2003).

In response to certain stimuli, the organism may induce $\mathrm{HO}-1$ to counteract the action of the stimuli in a feedback inhibition. For example, serum stimulates HO-1 gene expression and subsequent $\mathrm{CO}$ synthesis in cells such as smooth muscle cells (SMC). In these conditions, CO acts in a negative feedback fashion to inhibit vascular SMC.In another example, angiotensin infusion causeshypertension and also induces $\mathrm{HO}-1$ in the vasculature. Inhibition of $\mathrm{HO}-1$ with CORM aggravates the hypertensive effects of angiotensin, thus highlighting HO-1 as an antagonistic response to the stimulus(Yang, Quan, Nasjletti, Laniado-Schwartzman, \& Abraham, 2004).

\subsection{CO-releasing molecules: CO-RMs(Figure 2)}

Three distinct methods of delivering $\mathrm{CO}$ have been utilized in studies to date. Thesimplest method involves gaseous delivery at low concentrations.A second method ofdelivery is the use of CO gas-saturated physiological solutionswhich, whilst applicable in a transplant setting, would have limited application as a therapeutic agent. Alternatively, CO may be delivered to organ systems by chemical agents that release $\mathrm{CO}$. These include the COreleasing molecules (CORMs); these molecules being employed both in in vitro and in vivo studies.Transitional metal carbonyls based around iron, manganese or ruthenium, have recently been developed as CO-RMs that, under appropriate conditions, will release CO. Such molecules have been shown to provide cardioprotection in both ex vivo and in vivo experiments(Chatterjee, 2004; Motterlini, et al., 2005). The development of transition metal carbonyls as prototypic CO-RMs represents a novel stratagem for a safer delivery of CObased pharmaceuticals in the treatment of various pathological disorders(Foresti \& Motterlini, 2010). Recently, photosensitive CORMs (photo-CORMs: i.e.[Mn(pqa)(CO)3](ClO4); pqa=2-pyridylmethyl)(2-quinolylmethyl)amine ) have been employed to deliver CO to myoglobin under the control of light(Gonzalez, et al., 2012).

The results generated in the last few years indicate that CO-RMs possess effective vasodilatory, anti-ischemic and anti-inflammatory activities. Their pharmacological action 
may be associated with other important cytoprotective effects provided by small amounts of CO released.

Understanding chemicalinteractions of CORMs with proteinsis crucial for the design of pharmaceutical CORMs, which will ultimately circulate in the protein-rich plasma of humans. The interaction of CORM-3 with several plasma proteins that may play a central role in itstransport and activation in vivo(Santos-Silva, et al., 2011). In vitro, rapid formation of protein-Ru"(CO)2 adducts led to hypothesize that such protein adducts generated in vivo are the source of the reported $\mathrm{COHb}$ levels that were sustained over $24 \mathrm{~h}$ after a single dose of CORM-3(G. Wang, et al., 2010). Azido-modified silicium dioxide nanoparticles can be utilized as a carrier system for the Photo-CORMs (Dordelmann, Pfeiffer, Birkner, \& Schatzschneider, 2011). The generation of " $M(C O) 5$ " appeared to be a crucial step in the mechanism of COrelease, but it has been anticipated that species $[\mathrm{M}(\mathrm{CO}) 5 \mathrm{~L}$ ] (in which $\mathrm{L}$ is the biologically compatible leaving group such as an amino acid )would be an attractive target(W. Q. Zhang, Whitwood, Fairlamb, \& Lynam, 2010).CO can be applied through inhalation; however, the major disadvantage of this modality is that it directly competes with oxygen uptake in the lung. CORMs have the propensity to liberate $\mathrm{CO}$ in a controllable fashion. In particular, CORM-3, which is fully water soluble and allows intravenous administration, rapidly liberates CO. In CORM-3-stimulated HUVECs, p38 MAPK was inhibited (Bergstraesser, et al., 2012). This result is in conflict with previously published studies showing that CO activates p38 MAPK (Otterbein, et al., 2003). Differences in concentration, application form (gas vs. CORM3) and cell type could explain this controversy.

\section{3- Overview: catabolism of endogenous carbon monoxide.}

$\mathrm{CO}$ is the diatomic oxide of carbon. At temperatures above $-190^{\circ} \mathrm{C}$, CO is a colorless and odorless gas. The specific gravity of $\mathrm{CO}$ is 0.967 relative to air, and its density is $1.25 \mathrm{~g} / \mathrm{L}$ at standard temperature and pressure. $\mathrm{CO}$ is a chemically stable molecule because of its formal triple bond. Chemical reduction of $\mathrm{CO}$ requires temperatures well above $100^{\circ} \mathrm{C}$. The water solubility of $\mathrm{CO}$ is very low at standard temperature and pressure. CO cannot react with water without substantial energy input. Even for molecular oxygen, the reaction rate of $\mathrm{CO}$ is slow and needs high activation energy $(213 \mathrm{~kJ} / \mathrm{mol})$. CO can be involved in redox reactions 
andis an important signaling mediator possessing vasodilatory, anti-inflammatory, antiapoptotic and anti-proliferativeproperties(Barbagallo, Marrazzo, Frigiola, Zappala, \& Volti, 2012; H. P. Kim, Ryter, \& Choi, 2006; Mann \& Motterlini, 2007; Piantadosi, 2002; Ryter \& Otterbein, 2004).

Unlike the high reactivity of NO, which by itself is a free radical, CO does not contain free electrons.It has been reported that intracellular reactions may form carbonate radical anion from CO. Toxic and presumed sub-toxic $\mathrm{CO}$ exposures are associated with significant oxidative and nitrosative stress. After poisoning rats with CO (> $1000 \mathrm{ppm}$ ), plasma levels of oxidized proteins and lipid peroxidation were significantly increased(Thom, Fisher, Xu, Garner, \& Ischiropoulos, 1999). CO-induced increase in oxidative stress was not related to hypoxic stress from formation of carboxyhemoglobin or changes in circulating platelets or neutrophils. However, CO-dependent lipid peroxidation was prevented or reduced by inhibition of xanthine oxidase or superoxide dismutase and iron chelators. It has also been shown that intracellular $\mathrm{H}_{2} \mathrm{O}_{2}$ production in the brain was increased by high concentrations of $\mathrm{CO}$, accompanied by increases in hydroxyl radical production and decreases in the reduced to oxidized glutathione (GSH/GSSG) ratio in mitochondria(Piantadosi, Tatro, \& Zhang, 1995).

$\mathrm{NO}$ and $\mathrm{CO}$ have a high affinity for Fe. However, while both $\mathrm{CO}$ and $\mathrm{NO}$ bind Fe(II) avidly in hemoproteins, CO, unlike NO, does not bind to Fe(II) hemoproteins(Kajimura, et al., 2010; Watts, Ponka, \& Richardson, 2003).

In contrast with $\mathrm{CO}$, which exists as a stable neutral molecule, NO can be found in distinct redox-related states that have different reaction specificities. These forms of NO include nitric oxide ( $\left.{ }^{\circ} \mathrm{NO}\right)$, nitroxyl anion $\left(\mathrm{NO}^{-}\right)$and the nitrosonium ion $\left(\mathrm{NO}^{+}\right)$. Apart from the reaction with Fe and other transition metals, NO can react with dioxygen, superoxide and thiol groups.Unlike CO, which has a long half-life, the biological half-like of ${ }^{\bullet} \mathrm{NO}$ is in the order of seconds, and its reaction with superoxide generates peroxynitrite $\left(\mathrm{ONOO}^{-}\right)$. This latter species is highly reactive with cardiovascular actions(Lauzier, Sicard, Bouchot, Delemasure, Moreau, et al., 2007)and rapidly decomposes to result in the cytotoxic hydroxyl radical $\left({ }^{\circ} \mathrm{OH}\right)$ inducing biological effects(Pacher, Beckman, \& Liaudet, 2007).

In terms of the chemical interaction between $\mathrm{CO}$ and ${ }^{\bullet} \mathrm{NO}$, (Figure 3 ) it is known that $\mathrm{CO}$ can stimulate ${ }^{\circ} \mathrm{NO}$ release from proteins and the production of peroxynitrite. This could be 
critical in terms of mobilizing intracellular ${ }^{\bullet} \mathrm{NO}$ and be part of the synergistic interactions of these two molecules(Piantadosi, 2002). It has been suggested that CO could cause redistribution of ${ }^{\circ} \mathrm{NO}$ in cells, which is consistent with the different equilibrium constants of these molecules for metal binding. For instance, considering $\mathrm{Hb}$, the affinity of ${ }^{\bullet} \mathrm{NO}$ for $\mathrm{Fe}(\mathrm{II})$ is 1,500 times greater than CO. The presence of iron will dramatically influence the roles of -NO and CO, and, in turn, these signaling molecules will affect cellular iron metabolism.

Despite ${ }^{\circ} \mathrm{NO}$ having a higher affinity for heme-iron, a paradoxical effect of $\mathrm{CO}$ is its ability to displace ${ }^{\bullet} \mathrm{NO}$ after a period of time. This is because the association constant of ${ }^{\bullet} \mathrm{NO}$ for heme-Fe is greater than that of $\mathrm{CO}$, while the dissociation constant for ${ }^{\circ} \mathrm{NO}$ is also greater than that for $\mathrm{CO}$. Thus, as ${ }^{\bullet} \mathrm{NO}$ is displaced by $\mathrm{CO}, \mathrm{CO}$ remains bound to heme for a longer period of timeand this effect is implicated in its toxic action (see above: Production of COand "gas-sensors").

\section{4- Heme-oxygenase and cellular targets of $\mathrm{CO}$}

\subsection{Heme-oxygenase and cellular metabolism}

HO-1 mediates the degradation of free and protein-bound heme, and promotes the formation of protective compounds. Numerous studies have indicated that $\mathrm{HO}-1$ induction is an adaptive defense mechanism to protect cells and tissues against injury in many disease settings. Given that inflammation and oxidative stress are associated with development of cardiovascular disease and that HO-1 has anti-inflammatory and anti-oxidative properties, HO-1 is emerging as a great potential therapeutic target for treating cardiovascular diseases. The enzyme is important in the regulation of cell proliferation, differentiation and apoptosis. Its activity improves neovascularization and modulates the immune response, thereby influencing carcinogenesis(Cairo, Recalcati, Mantovani, \& Locati, 2011; Koliaraki \& Kollias, 2011; M. L. Wu, Ho, Lin, \& Yet, 2011).

Involvement of the HO-adiponectin-EET axis 
Recent studies have also identified a beneficial role for $\mathrm{HO}-1$ in the regulation of body weight and metabolism in diabetes and obesity. Chronic HO-1 induction lowers body weight and corrects hyperglycemia and hyperinsulinemia. Chronic HO-1 induction also modifies the phenotype of adipocytes in obesity from one of large, cytokine producing to smaller, adiponectin producing(Hosick \& Stec, 2012). The pharmacological enhancement of HO-1 expression, resulting in a phenotype resistant to injurious stimuli, permits the heart to initiate an immediate defense against the events associated with the metabolic syndrome(Cao, et al., 2011).

Emerging studies indicate a role of lipid mediators in the regulation of metabolic homeostasis; thereby warranting further examination of their biological role in conditions such as obesity. The levels of $\mathrm{HO}-1$ expression, $\mathrm{HO}$ activity and its products, $\mathrm{CO}$ and bilirubin, are decreased in humans and in animal models of type-2 diabetes (Kruger, et al., 2006).In conclusion, induction of HO-1 appearsmodulate metabolic syndrome, obesity, and insulin resistance. The changes that are observed after increased expression of $\mathrm{HO}-1$ in obese and diabetic animal models include:prevention of weight gain, reduction of inflammatory cytokines levels andrestoration of normal insulin sensitivity. Taken together,the recent dataprovide definitive evidence for the involvement of the HO-adiponectin-EET axis in adipogenesis and adipocyte signaling both in vitro and in vivo(Burgess, Vanella, Bellner, Schwartzman, \& Abraham, 2012).

New approach of HO-1 functionwith a cell-permeable pyrrazo-lopyrimidine derivative: compound $C$

Recently, a new approach of HO-1 functions had been possible using a compound that is able to stimulate the expression of $\mathrm{HO}-1$ in these cells. This compound $\mathrm{C}$ has been identified as a cell permeable inhibitor of adenosine monophosphate-activated protein kinase (AMPK) and a novel inducer of heme oxygenase-1 (HO-1). Surprisingly, the compound C (6-[4-(2piperidin-1-yl-ethoxy)-phenyl]-3-pyridin-4-yl-pyrazolo[1,5-a] pyrimidine), could also elevate HO-1 suggesting other AMPK-independent actions for this agent. In human endothelial cells, compound $\mathrm{C}$ stimulated a concentration- and time-dependent increase in HO-1 expression and an increase in HO-1 promoter activity. The ability of compound $\mathrm{C}$ to induce $\mathrm{HO}-1$ expression may contribute to the pleiotropic actions of this agent and suggest caution when 
using compound C to probe for AMPK functions (Liu, Peyton, Shebib, Wang, \& Durante, 2011).

Compound $\mathrm{C}$ exerts potent anti-proliferative and pro-apoptotic effects in various cell lines (Jang, et al., 2010). Interestingly, treatment of endothelial cells with compound C results in a concentration- and time-dependent increase in HO-1 mRNA and protein. The induction of HO-1 expression by compound $\mathrm{C}$ is dependent on oxidative stress. Compound $\mathrm{C}$ induces a progressive increase in the production of ROS that is paralleled by a decline in intracellular glutathione (GSH) level associated with endothelial cell death. GSH serves several vital functions including scavenging free radicals(S. C. Lu, 2009). Compound C-mediated endothelial cell death is potentiated following knockdown of HO-1 expression, indicating that the induction of $\mathrm{HO}-1$ by compound $\mathrm{C}$ promotes cell survival; the cytoprotective action of HO-1 being mediated via the formation and actions of bilirubin and CO. Ferrous iron, a pro-oxidative molecule, is released during the breakdown of free heme by $\mathrm{HO}-1$, but this molecule is rapidly, as we reported, removed by ferritin, an ubiquitously existing intracellular protein that is able to effectively sequester intracellular iron and, hence, limits the prooxidant capacity of ferrous iron. There is evidence showing that increased ferritin expression in conjunction with HO-1 expression contributes to the protective effect of HO-1 (Balla, et al., 2007)

\subsection{Heme- Oxygenase and endothelium}

HO-1 is highly expressed in the endothelium, macrophage, and foam cells of atherosclerotic plaques in both humans and animals. In the vascular system, HO-1 and heme degradation products perform important physiological functions, which are ultimately linked to the protection of vascular cells(M. L. Wu, Ho, \& Yet, 2011). Studies have shown that HO-1 and heme degradation products exert vasodilatory effects on vascular cells. There are different possible mechanisms for $\mathrm{HO}$-induced changes in $\mathrm{Ca}^{2+}$ - activated potassium channels with a large conductance (KCa channels) of smooth muscle cells such ascGMP-dependent protein kinase (PKG) pathway, where CO triggers SGC activation, leading to an increase in intracellular cGMP content and subsequent activation of PKG. PKG may modulate KCa 
channel(Figure 4).Interestingly, these effects of HO-1 and its by-products are similar, at least in part, to those of eNOS-derived NO.

The human HO-1 deficiency reveals a critical immunomodulatory role of $\mathrm{HO}-1$ and highlights the essential function of HO-1 in human health and disease(Radhakrishnan, et al., 2011). HO1 expression is observed throughout the development of lesions from early fatty streaks to advanced complex atherosclerotic lesions. HO-1 is specifically upregulated in human vulnerable atherosclerotic lesions with lipid and macrophage accumulation and low collagen and vascular smooth muscle cell content(L. J. Wang, Lee, Lee, Pai, \& Chau, 1998).An important mechanism by which HO-1 exerts an anti-atherogenic effect is by arresting inflammation. HO-1 inhibits monocyte chemotaxis and leukocyte adhesion to activated vascular endothelium.Considerable evidence suggests now,in relationship withantiproliferative effects, that HO-1 plays a beneficial role in atherosclerosis(Durante, 2010).

Because the beneficial effects of HO-1 and heme degradation products are similar, at least in part, to those of eNOS and eNOS-derived ${ }^{\bullet} \mathrm{NO}$, a possible relationship between eNOS andHO1 pathways exists.There are several factors accounting for uncoupled eNOS, e.g. reduced levels of the NOS substrate L-arginine or the cofactor tetrahydrobiopterin. Another potential factor receiving increased attention is the accumulation of the endogenous inhibitor of eNOS, asymmetric dimethylarginine (ADMA). ADMAis an endogenous modulator of endothelial function and oxidative stress, and increased levels of this molecule have been reported in some metabolic disorders and cardiovascular diseases (Korandji, et al., 2011; Korandji, et al., 2007; Sicard, et al., 2008; Zeller, et al., 2008).Interestingly, the activity of the enzymes involved in the formation and degradation of ADMA such as protein arginine methyltransferases (PRMTs) and dimethylarginine dimethylaminohydrolase (DDAH) has been shown to be regulated in a redox-sensitive fashion. It has been reported that endothelial aging-induced increase in ROS formation was accompanied with an enhanced expression as well as enzymatic activity of HO-1.ADMA and homocysteine increased these changes(Scalera, et al., 2006).

Several strategies can be employed to target HO-1 in vascular disease (Durante, 2010).One promising approach involves the use of pharmacological inducers. Heme and its synthetic analogues are potent inducers of $\mathrm{HO}-1$ and have been shown to protect against the development of vascular disease in numerous animal models. In addition to upregulating 
HO-1 expression, heme is a substrate for HO-1 and this may serve to further enhance the synthesis of $\mathrm{CO}$ and bilirubin since HO-1 activity may be substrate-limited in vascular cells. Hemin is already approved for the treatment of acute porphyria and heme compounds have been used to treat thalassemia andmyelodysplastic syndrome(Rund \& Rachmilewitz, 2000). Endothelial cells can synthesize calcitonin gene-related peptide (CGRP); this peptide could protect against endothelial dysfunction induced by lysophosphatidylcholine (LPC) or oxidized low-density lipoprotein(Ye, et al., 2007).CGRP has anti-apoptotic properties and inhibits phosphatidylserine externalization, caspase 3 activation and DNA fragmentation due to oxidative stress(Sueur, Pesant, Rochette, \& Connat, 2005). It has been suggested that, in some tissues, induction of alpha-CGRP mRNA expressionassociated with cellular protection may involve the HO-1/COpathway(Peng, Lu, Ye, Deng, \& Li, 2002).

4.3. Heme-oxygenase, endothelial progenitor cells and multipotent marrow stroma stem cells (MSCS)

\section{Endothelial progenitor cells}

HO-1 is thought to protect the vessels via promoting re-endothelialization, inducing antiinflammatory activities, inhibiting smooth muscle cell proliferation associated withincreasing cellular antioxidant activities. Re-endothelialization of a denuded arterial surface is achieved by the migration and proliferation of cells from the injury border zone, or from adjacent branching blood vessels. In addition, bone marrow-derived endothelial progenitor cells (EPCS) can contribute to re-endothelialization.The number of circulating EPCs inversely correlates with the risk for atherosclerosis and the extent of ischemia after myocardial infarction(Kawamoto \& Asahara, 2007). Several compounds, including erythropoietin and statins, promote EPC mobilization and increase circulating EPCs. Interestingly, erythropoietin and statins can induce HO-1 expression, raising the possibility that their ability to mobilize EPCs is mediated at least in part via HO-1 induction(B. J. Wu, et al., 2009).Diabetes is associated with a decrease in circulating EPCs and EPC function that may contribute to vascular disease.HO-1 induction is known to attenuate inflammation and oxidative stress thought to contribute to diabetes(Grochot-Przeczek, Dulak, \& Jozkowicz, 2010). Recently in an attempt to identify the downstream effector of $\mathrm{HO}-1$, experiments were performed to 
test the effect of CO(Lin, Chen, Yet, \& Chau, 2009). The results showed that exposure of mice to a low dose of $\mathrm{CO}$ for $2 \mathrm{~h}$ day, 1 for 4 consecutive days led to the elevated serum level of SDF-1 but not VEGF. In parallel, circulating EPCs were significantly increased and contributed to the accelerated re-endothelialization observed in the CO-treated mice after vascular injury. These results support the theory that CO mediates at least in part the enhanced vascular repair induced by $\mathrm{HO}-1$.

\section{Multipotent marrow stroma stem cells (MSCs)}

The heme-HO system serves as an important cellular antioxidant defense system in obesityand diabetes. However, little is known about whether deficits in the cytoprotective systems of $\mathrm{HO}$ are implicated in the biology of multipotent marrow stromal stem cells: MSCs.MSCs are recognized as a crucial component of the bone marrow microenvironment, and directly contribute to the development of hematopoietic stem cells.Many cells and interactions within the bone marrow are still unknown; a delicate balance must exist within this system to maintain homeostasis. It has been suggested that diseases such as diabetes types 1 and 2, and other autoimmune diseases are actually disorders in stromal MSCs and their microenvironment(Ikehara, 2010). Bone marrow derived MSCs are particularly susceptible to oxidative stress caused by bone marrow toxicity due to environmental pollutants such as azitothymine (AZT), irradiation and chemotherapeutic drugs.It has been reported that anemia and neutropenia, occurring as a result of AZT treatment, could be reversed by the induction of HO-1 by hemin(Kemp, Morse, Sanders, Hows, \& Donaldson, 2011). A decrease in HO-1 expression is frequently associated with increased superoxide production and oxidative stress leading to impairment of MSCs function in bone marrow.HO1 appears as an important enzyme in protecting against oxidative stress caused by the generation of free radicals and bone marrow toxicity, by providing a rich environment for MSC growth and stem cell differentiation(Kansanen, Jyrkkanen, \& Levonen, 2012).

\section{5 - $\mathrm{CO}$, interaction with endogenous compounds and functions}

5.1 - Carbonate radical anion $\left(\mathrm{CO}_{3}{ }^{--}\right)$production and interaction with endogenous compounds(Figure 5) 
Bicarbonate anion $\left(\mathrm{HCO}_{3}{ }^{-}\right)$is present in high concentrations $(25 \mathrm{mM})$ in biological tissues. The role of bicarbonate anion in biological oxidation has largely been ignored. The relationship between the metabolism of carbonate and ROS has been recently studied in particular concerning the activity of antioxidant enzymes. A new perspective on the role of bicarbonate anion in SOD1-catalyzed peroxidative reactions was recently proposed.The copper-bound oxidant $\left(\mathrm{Cu}^{2+}-{ }^{\circ} \mathrm{OH}\right)$ could oxidize $\mathrm{HCO}_{3}{ }^{-}$to the carbonate anion radical $\mathrm{CO}_{3}{ }^{\circ}$, a potent oxidant that diffuses out of the active site and causes substrate oxidations. The fact that $\mathrm{CO}_{3}{ }^{--}$(and not ${ }^{\circ} \mathrm{OH}$ ) is the primary oxidant produced by SOD1-mediated peroxidase activity is physiologically significant because $\mathrm{CO}_{3}{ }^{-}$has a much longer half-life than the ${ }^{\circ} \mathrm{OH}$ and can, therefore, diffuse away from the active site and modify cellular targets(H. Zhang, Andrekopoulos, Joseph, Crow, \& Kalyanaraman, 2004).

A variety of micro-organisms possess the ability to oxidize $\mathrm{CO}$ to $\mathrm{CO}_{2}$. In aerobic bacteria, the oxidation is catalyzed by $\mathrm{CO}$ oxidase, an inducible molybdenum-containing enzyme that couples the oxidation of $\mathrm{CO}$ to the reduction of oxygen. Moreover, heart cytochrome $\mathrm{C}$ oxidase possesses the ability to convert $\mathrm{CO}$ to $\mathrm{CO}_{2}$ (Motterlini, et al., 2003; Young \& Caughey, 1986).

$$
\mathrm{CO}+\mathrm{H}_{2} \mathrm{O} \rightarrow \mathrm{CO}_{2}+\mathrm{H}_{2}
$$

or

$$
\mathrm{CO}+\mathrm{H}_{2} \mathrm{O} \rightarrow \mathrm{CO}_{2}+2 \mathrm{H}^{+}+2 \mathrm{e}^{-} \text {(Water Gas Shift Reaction) }
$$

In biological systems where multiple free radicals were present, the recombination reaction of superoxidewith another radical such as ${ }^{\bullet}$ NOis very fast. ${ }^{\bullet} \mathrm{NO}$ can be toxic through reaction with superoxide to generate peroxynitrite $\left(\mathrm{O}=\mathrm{NOO}^{-}\right)$, an oxidizing agent capable of modifying a variety of biological molecules. An interesting concept is that ${ }^{\bullet} \mathrm{NO}$ protects against the toxicity ofO $_{2}{ }^{--}$by scavenging it to form $\mathrm{O}=\mathrm{NOO}^{-}$, which in part spontaneously decomposes to $\mathrm{NO}_{3}{ }^{\circ-}$. The reaction of ${ }^{\circ} \mathrm{NO}$ with reactive species such as nitrogen dioxide $\left({ }^{\circ} \mathrm{NO}_{2}\right)$ and nitrogen trioxide $\left(\mathrm{N}_{2} \mathrm{O}_{3}\right)$ may have biological significance. ${ }^{\bullet} \mathrm{NO}$ is a more reactive 
and a more powerful oxidant that is ${ }^{\circ} \mathrm{NO}$. This implies that when both $\mathrm{O}_{2}{ }^{- \text {- }}$ and ${ }^{\circ} \mathrm{NO}_{2}$ are present in the same environment, they will most likely react to form peroxynitrate.

$$
\mathrm{NO}_{2}+\mathrm{O}_{2}^{\cdot-} \rightarrow \mathrm{O}_{2} \mathrm{NOO}^{-}
$$

The mechanism for the reaction of peroxynitrite with $\mathrm{CO}_{2}$ was ignored for several years and the reactions of peroxynitrite in biological were investigated in vitro in solutions that contained $\mathrm{CO}_{2}$ in presence and absence of bicarbonate buffers. Initially, the carbonate radical anion has been produced in vitro by radiolysis of aqueous solutions of bicarbonate/carbonate(S. N. Chen \& Hoffman, 1973).The modulation of peroxynitrite and peroxynitratereactivity by $\mathrm{CO}_{2}$ has been studies. In the presence of $\mathrm{CO}_{2}$, peroxynitrite generates the $\mathrm{CO}_{3}{ }^{\circ-}$ and ${ }^{\circ} \mathrm{NO}_{2}$ radicals in a fast reaction. These two radicals constitute an efficient nitrating system with biological nitration of protein tyrosine residues. The reaction of $\mathrm{CO}_{2}$ with peroxynitrite is fast, resulting in the formation of ${ }^{\circ} \mathrm{NO}_{2}$ and $\mathrm{CO}_{3}{ }^{-}$in the medium from the facile decomposition of the initially formed adduct, 1-carboxylato-2nitrosodioxidane $\left(\mathrm{ONOOCO}_{2}{ }^{-}\right)$(Surmeli, Litterman, Miller, \& Groves, 2010). So, under physiological conditions, where the concentration of $\mathrm{CO}_{2}$ is high, a rapid reaction of peroxynitrite with $\mathrm{CO}_{2}$ occurs.

$$
\mathrm{ONOO}-\mathrm{CO}_{2} \rightarrow\left[\mathrm{ONOOCO}_{2}^{-}\right] \rightarrow \mathrm{NO}_{2}+\mathrm{CO}_{3}^{\cdot-}
$$

Carbonate radicals can be also formed when ${ }^{\circ} \mathrm{OH}$ reacts with carbonate or bicarbonate ions. As we reported above, bicarbonate levels in blood plasma are high making reaction possible(Meli, Nauser, Latal, \& Koppenol, 2002; Radi, Peluffo, Alvarez, Naviliat, \& Cayota, 2001).

$$
\mathrm{CO}_{3}{ }^{2-}+{ }^{\bullet} \mathrm{OH} \rightarrow \mathrm{CO}_{3}^{\cdot-}+\mathrm{OH}^{-}
$$

$\mathrm{CO}_{3}{ }^{\bullet-}$ havinga much longer half-life than ${ }^{\circ} \mathrm{OH}$, it diffuses further from the enzyme active site and can oxidizethedistant cellular targets. The order of reactivity is ${ }^{\circ} \mathrm{OH}>\mathrm{CO}_{3}{ }^{-}>{ }^{\bullet} \mathrm{NO}_{2}$ and these radicalspresenta selectivityfor certain biomolecules. $\mathrm{CO}_{3}{ }^{\circ}$ and ${ }^{\circ} \mathrm{NO}_{2}$ react faster with 
some amino acids such as tyrosine, tryptophan and cysteine than they do with alanine and glycine. It has been reported thatCO ${ }_{3}{ }^{\circ-}$ can abstract ${ }^{\circ} \mathrm{H}$ from cysteine.

$$
\text { Cys-SH }+\mathrm{CO}_{3}{ }^{--} \rightarrow \mathrm{HCO}_{3}^{-}+\mathrm{cys}^{-} \mathrm{S}^{\bullet}
$$

Carbonate radical is also involved in the activity of Cu-Zn SOD(Ramirez, Gomez Mejiba, \& Mason, 2005). The bicarbonate-dependent peroxidative activity of SOD1 has been explained on the bases of bicarbonate to carbonate radical anion occurs at the enzyme active site by reaction with the $\mathrm{H}_{2} \mathrm{O}_{2}$-induced enzyme - copper bound oxidant.It has been demonstrated that the oxidase activity of SOD1 stimulates carbonate anion radical formation in the presence of $\mathrm{HCO}_{3}{ }^{-}$. The $\mathrm{CO}_{3}{ }^{--}$formed in the SOD $1 / \mathrm{Cys} / \mathrm{HCO}_{3}{ }^{-}$system is responsible for oxidation and hydroxylation reactions(Chandran, et al., 2010).

$$
\mathrm{Cu}(\mathrm{II})-\mathrm{SOD} 1 /{ }^{\circ} \mathrm{OH}+\mathrm{HCO}_{3}^{-} \rightarrow \mathrm{Cu}(\mathrm{II})-\mathrm{SOD} 1-\mathrm{OH}+\mathrm{CO}_{3}{ }^{-}
$$

The interest in carbonate radical anion is being renewed. The carbonate radical anion in particular is a potent one-electron oxidant whose reducing potential at $\mathrm{pH} 7.0(\mathrm{E}=1.78 \mathrm{~V})$ is not much smaller than that of the hydroxyl radical $(E=2.3 \mathrm{~V})$ and is considerably higher than that of nitrogen dioxide $(E=0.99 \mathrm{~V})$.

\subsection{Carbonate radical anion: $\mathrm{CO}_{3}{ }^{--}$and cellular functions}

During myocardial reperfusion, the increased flux of free radicals(Opie, 1989; C Vergely, Perrin-Sarrado, Clermont, \& Rochette, 2002; C Vergely, et al., 2003), which reacts with ${ }^{\circ}$ NO enhances the formation of $\mathrm{ONOO}^{-}$. These peroxynitrite ions are decomposed as previously mentioned. ${ }^{\circ} \mathrm{NO}_{2}$ and $\mathrm{CO}_{3}{ }^{\circ-}$ are formed within the heart and may exert deleterious effects. $\mathrm{A}$ nitroxide compound such as 4-hydroxy-2,2,6,6-tetramethylpiperidine-1-oxyl (TPL) in presence of arginine significantly improved the recovery of hemodynamic function of hearts following ischemia-reperfusion. The kinetics of the reaction of $\mathrm{CO}_{3}{ }^{-}$with TPL has been studied and it has been demonstrated that TPL is an efficient scavenger of $\mathrm{CO}_{3}{ }^{-{ }^{-}}$(Hoffman, Goldstein, Samuni, Borman, \& Schwalb, 2003). 
Reactions of the carbonate radical anion with transition metal ions in metalloproteins are also predictable but they have been little studied thus far. The reaction of the carbonate and dichloride radical anions with the extracellular matrix glycosaminoglycan hyaluronan (HA) had been studied in vitro(Al-Assaf, Navaratnam, Parsons, \& Phillips, 2006). These radicals were found to react quickly with HA inducing a scission of HA. Next, we will focus on some aspects related to thedegradation products of glycosaminoglycans.

It has been reported that carbonate anion was potentially animportant oxidant of nucleic acids in physiological environments. The $\mathrm{CO}_{3}{ }^{--}$radicals oxidize guanine bases of DNA through a one-electron transfer reaction process that ultimately results in the formation of stable guanine oxidation product, proteins and nucleic acids beinglikely main targets at this radical (Hoffman, et al., 2003).

There is solid evidence supporting the formation of many free radicals by cells leading to the view that they play an important role in cell homeostasis(Halliwell, 2007b; Jay, Hitomi, \& Griendling, 2006). In addition into focus reactive species, the recent studies of the biochemical reactions of ${ }^{\bullet} \mathrm{NO}$, carbonate radical and hydrogen posed that these compounds contribute to the pathogenesis of diseases pro has including inflammatory processes, ischemia-reperfusion and cardiovascular disorders(Hart, 2011; Leffler, Parfenova, \& Jaggar, 2011). As we reported, pro-oxidant states have been described following the inhalation of toxic doses of CO, possibly by neutrophil recruitment(Thom, Fisher, Xu, Notarfrancesco, \& Ischiropoulos, 2000).In return, low doses of CO protect against hyperoxia-induced endothelial cell apoptosis by inhibiting reactive oxygen species formation(X. Wang, et al., 2007).

Recent studies implicate ROS-dependent signaling in the stimulation of mitochondrial biogenis by $\mathrm{CO}$ via $\mathrm{CO}_{3}{ }^{-1}$ through redox-dependent activation of the nuclear respiratory factor 1 (NRF1) (Rhodes, et al., 2009). A role for autophagic regulator proteins in CO-dependent cytoprotection has been recently reported (S. J. Lee, et al., 2011). This study uncovers a new mechanism for the protective action CO via mitochondrial ROS formation (Cooper \& Brown, 2008). Manganese superoxide dismutase (MnSOD) plays a critical role in cellular defense against oxidative stress by decomposing superoxide within mitochondria.The degree of activity of this enzyme is modified by the action of $\mathrm{CO}_{3}{ }^{-}$(Surmeli, et al., 2010). This review will discuss these different mechanisms in the context of the paragraph: Signalingto Heme Oxygenase-1 and $\mathrm{CO}$. 
In addition, it is important to include a new research field that seeks to define the relationship between the physiological properties of $\mathrm{CO}_{\text {and }} \mathrm{CO}_{3}{ }^{-}$as emerging regulators of ion channels and the alteration of the redox state of the cell;proteins being likely the main biotargets ofCO $_{3}{ }^{-1}$ (Augusto, et al., 2002; Wilkinson \& Kemp, 2011). There have been a number mechanisms proposed to explain how $\mathrm{CO}_{3}{ }^{\circ-}$ modifies these targets associated with alteration of the redox sate of the cell and organites such as mitochondria(Radi, Cassina, Hodara, Quijano, \& Castro, 2002). The diffusion capacity of $\mathrm{CO}_{3}{ }^{-}$and ${ }^{\circ} \mathrm{NO} 2$ radicals is secondary to the peroxynitrite $/ \mathrm{CO}_{2}$ reaction and the two radicals diffuse across mitochondrial membrane. Reactions in mitochondria involve either transition-metal dependent pathways or the $\mathrm{CO}_{2}$-dependent formation and reactions of $\mathrm{CO}_{3}{ }^{\circ-}$ and ${ }^{\circ} \mathrm{NO}_{2}$ radicals.An important factor in the active mitochondrial biogenesis program initiated by COis HO-1 induction. In this field, $\mathrm{HO}-1 / \mathrm{CO}$ has been implicated in the adjustment of mitochondrial phenotype to oxidative stress(Piantadosi, 2008). In the mitochondria, CO inhibits cytochrome c-oxidase (COX). CO is converted to carbon dioxide by COX after binding. In physiological conditions, "free" CO concentration is very low due to its high affinity for hemoglobin and myoglobin. In return, in toxic conditions, the CO concentration in tissues could increase so much as to cause significant inhibition. A number of enzymes have also been shown to be modulated by $\mathrm{CO}$ and CO-RMs. There have been reported suggesting that CO decrease ROS production by inhibiting NADPH oxidase thereby limiting ROS generation(Srisook, et al., 2006).

Recent studies have shown that peroxynitrite can lead to protein nitration and inactivation; $\mathrm{CO}_{3}{ }^{\circ}$ and ${ }^{\circ} \mathrm{NO}_{2}$ radicals being implicated in the process. The tyrosine nitration may also be mediated by nitrogen dioxide produced by the oxidation of nitrite by peroxidases. Manganese superoxide dismutase (MnSOD), which plays a critical role in cellular defense against oxidative stress by decomposing superoxide within mitochondria, is nitrated and inactivated under pathological conditions. Three of the seven tyrosine residues of MnSOD ( $\mathrm{Tyr}_{34}, \mathrm{Tyr}_{9}$, and $\mathrm{Tyr}_{11}$ ) were the most susceptible to nitration. Nitration mediated byperoxynitrite, in both the presence and absence of $\mathrm{CO}_{2}$, resulted in nitration of the active site tyrosine, $\mathrm{Tyr}_{34}$. The nitration of $\mathrm{Tyr}_{34}$ by peroxynitrite $-\mathrm{CO}_{2}$ showed that the nitration rate coincided with the kinetics of the reaction ofperoxynitrite with $\mathrm{CO}_{2}$ (Surmeli, et al., 2010). Kinetics in the efficiency of tyrosine nitration in the presence of $\mathrm{CO}_{2}$ suggest a specific role forCO$_{3}{ }^{-}$in MnSOD nitration by peroxynitrite(Surmeli, et al., 2010).Protein tyrosine nitration 
has been observed in connection with numerous human diseases including neurodegenerative conditions, cardiovascular disorders and diabetes(Y. Li, et al., 2010).

Considerable evidence exists for oxidative damage to extracellular and intracellularmaterialsduring multiple human pathologies.The biomolecular damage can result on minimal and reversible changes to cell and tissue physiology. Consequently, although $\mathrm{CO}_{3}{ }^{-}$can oxidize manybiological targets. The carbonate radical anion is an important oxidizing agent in aqueous environments; consequently, it is unlikely to be an efficient initiator of lipid peroxidation.An important effect of $^{-}{ }_{3}{ }^{-}$is to increase nitrogen dioxide efficiency in nitrating protein-tyrosine and nucleic acid-guanine residues(Augusto, et al., 2002).

Nutrition of articular cartilage as avascular tissue containing chondrocytes embedded into a large amount ofextracellular matrix is dependent on diffusion from synovial and subchondral bone compartment. Oxygen and metabolic end products have to diffuse over relative long distances, resulting in low $\mathrm{O}_{2}$ tension in cartilage tissue. A rise of $\mathrm{O}_{2}$ tension in cartilage tissue as is typical for inflammation in chronically irritated joints enhances free radical formation, an interesting finding in the context of cartilage degeneration(S. Zhou, Cui, \& Urban, 2004). Glycosaminoglycansand hyaluronan are major components of the extracellular matrix and cartilage. These materials provide strength and elasticity to tissues and play a key role in regulating cell function.It has already been established that degradation products of glycosaminoglycans, and particularly lower molecular mass species, can have potent biological effects. A number of studies have investigated the reaction of HO., produced by a variety of mechanisms, with hyaluronan. There is new information concerning how $\mathrm{CO}_{3}{ }^{\circ}$ may induce depolymerization of hyaluronan and other glycosaminoglycans. The presence of $\mathrm{CO}_{2}$, and consequent formation of $\mathrm{CO}_{3}{ }^{\circ}$, has been reported to enhance $\mathrm{ONOO}^{-} / \mathrm{ONOOHinduced}^{\circ}$ protein damage(Kennett \& Davies, 2009).In a recent study, it has been demonstrated that hyaluronan and chondroitin sulfate were extensively depolymerized by $\mathrm{CO}_{3}{ }^{-{ }^{-}}($Kennett \& Davies, 2009). In fact, hyaluronanitself acts as an ROS scavenger in the joint by competing with other substrates for reaction with ROS. Joints appear to be capable of adapting to oxidative stress induced by extrinsic factors if they have not been pathologically altered(Ziskoven, et al., 2011). It is clear from recent data obtained that many of the sugar derived radicals formed are common across the oxidants examined. $\mathrm{CO}_{3}{ }^{--}$is capable of 
generating sugar-derived radicals, these radicals being formed in ratios different from that observed with HO(Kennett \& Davies, 2009).

\subsection{ROS and CO: regulators of inflammation}

Novel insights have led to the suggestion that ROS are important regulators of inflammation and are involved in limiting the inflammatory response(Hultqvist, Olsson, Gelderman, \& Holmdahl, 2009). Increasing amounts of data indicate that NOX2-produced ROS are beneficial in both inflammatory and autoimmune conditions. The NOX2 enzymatic complex is responsible for the reduction of the oxygen, yielding superoxide anion that is subsequently transformed into other ROS such ashydrogen peroxide and the hydroxyl radical. The NOX2 complex is composed of five subunits, two of which (p22 phox and gp91 phox ) are localized in cellular membranes, constituting the flavocytochrome b558(Al Ghouleh, et al., 2011). Hypothetically, ROS are beneficial during antigen presentation and affect the response and reactivity of the T-cell and the other hand, redox levels affect the T-cell receptor (TCR) signaling (Reyes, Danese, Sans, Fiocchi, \& Levine, 2005).Furthermore, ROS not only affect the TCR signaling structures but also promote the assembly of the T-cell-activation complex within the lipid rafts (S. P. Lu, et al., 2007) and the clustering of proteins(Nakashima, et al., 2002). It has beendemonstratedthat $\mathrm{HO}-1$ and $\mathrm{CO}$ inhibit the production of cytokines critical for T-cell responses. Increased expression of HO-1 by mouse macrophages or treatment of these cells with $\mathrm{CO}$ inhibits the production of pro-inflammatory cytokines induced by LPS stimulation(Inoue, et al., 2001). In conclusion,ROSproduced by antigen-presenting cells are able toaffect the activation and reactivity of T cells during antigen presentation;ROS appear as regulators of autoimmune inflammation.

\section{Signalingto heme-oxygenase-1 and $\mathrm{CO}$ (Figure 6).}

\subsection{Signalingto heme-oxygenase-1}


The induction of HO-1 expression is an important aspect of the anti-inflammatory, antiapoptotic response to cellular stress. The gene coding for HO-1 is highly regulated, and in most cell types, HO-1 is expressed in response to numerous stimuli(H. P. Kim, et al., 2006; Ryter, Alam, \& Choi, 2006). Regulation of the HO-1 gene is predominantly at the transcriptional level. Various transcription factors will interact with DNA binding domains in the HO-1 promoter to regulate gene transcription. A number of signaling molecules have been identified to be involved in regulating $\mathrm{HO}-1$ expression. We report herein some of the transcription factors and protein kinases involved in the regulation of vascular $\mathrm{HO}-1$ expression. These molecules include mitogen-activated protein kinases (MAPKs), nuclear factor E2-related factor 2 (Nrf2), Bach1, protein kinase C, protein kinase A, phosphatidyl inositol 3-kinase, Akt, activator protein-1 (AP-1), nuclear factor- $\kappa B(N F-\kappa B)$, cyclic adenosine monophosphate-responsive element-binding protein and activating transcription factor 2 . There is significant interplay between these signaling pathways, transcription factors and the production of inflammatory molecules and/or reactive oxygen species. It is not clear how these interactions play out in response to toxins and/or nutrients, these interactions being pivotal in determining the inflammatory response in a tissue(Spencer, Vafeiadou, Williams, \& Vauzour, 2012). It is most likely that HO-1 expression may result from the complex cooperative interactions between these molecules(Y. M. Kim, et al., 2011).

\section{MAPKs}

It has been known that activation ofmitogen activated protein kinase (MAPKs) plays a central role for the induction of HO-1 gene expression(Coulthard, White, Jones, McDermott, \& Burchill, 2009; Kyriakis \& Avruch, 2001). The intracellular communication between membranereceptors and their nuclear or cytoplasmic targets upon stimulation is mediated by a limited number of signaling pathways, including a group of MAPK cascades. This group includes 4 distinct cascades, which are named after their MAPK stage component: 1) extracellular-signal-regulated kinase 1 and 2 (ERK1/2); 2) c-Jun $\mathrm{N}$-terminal kinase 1 to 3 (JNK1-3); 3) p38MAPKand 4) ERK5 (Big MAPK)(Wortzel \& Seger, 2011). In normal physiology, MEK5 and ERK5 are ubiquitously expressed and are activated by growth factors and cellular stresses. It appears that the MEK5/ERK5 pathway plays an important role in tumor neovascularization(Lochhead, Gilley, \& Cook, 2012) and inflammation.The mitochondria is a point of integration of signaling cascades because of its pivotal role in cellular metabolism, 
redox biochemistry, and survival/death decisions(Smith, Ng, Kluck, \& Nagley, 2008). Because the MAPK family of signaling molecules: phospho-p38 MAPK, and ERK, play essential roles in cell signaling pathways that regulate cell growth and inflammation,an important point has been studied concerning the MAPK signaling pathway associated with the actions of CO.The anti-inflammatory effect of $\mathrm{CO}$ did not mediate through a guanylyl cyclase pathway, butinstead through the p38 MAPK in lipopolysaccharide (LPS)-activated macrophages(Otterbein, et al., 2000).

Similar to HO-1, p38 MAPK has been shown to be involved in antioxidant and antiinflammatory responses. Studies have focused on the roles of MAPK pathways in HO-1 expression in diverse cell types in response to variousstimuli. Several antioxidantssuch as curcumin and lipoic acidhave been reported to induce HO-1 expression in various types of cells.Curcumin stimulates HO-1 expression through p38 MAPK pathway(Jeong, et al., 2006). $\alpha$-Lipoic acid, that exerts antioxidant effects in biological systems(Ghibu, et al., 2012; Ghibu, et al., 2009), induces HO-1 expression through ERK pathway (Ogborne, Rushworth, \& O'Connell, 2005).

\section{NF-KB}

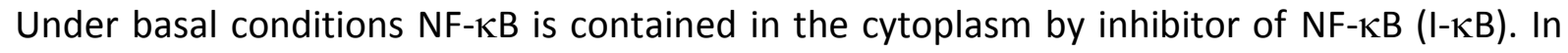
response to a wide range of signals, the regulatory NF- $\mathrm{KB}$ subunits $\mathrm{p} 50$ and $\mathrm{p} 65$ dissociate from $\mathrm{I}-\kappa \mathrm{K}$ and subsequently translocate to the nucleus.Oxidative stress including lipid peroxidation products or depletion of reducedglutathione (GSH) and subsequent increases in cytosolic oxidized form: GSSG in response to oxidative stress causes rapid ubiquitination and

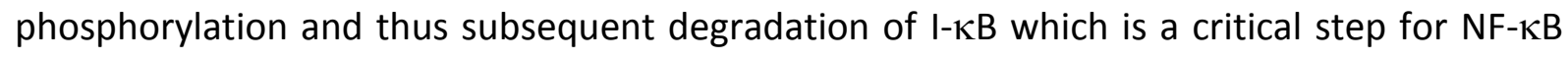
activation. By modulating a wide variety of transcription factors, cellular metabolism may be regulated. In this field, the $\mathrm{HO}$ system may be crucial for the coordination of physiological conditions. Given that $\mathrm{HO}-1$ is induced by different stimuli, the regulation of NF-KB by HO-1 may be important for cellular homeostasis in many pathophysiological conditions including inflammation.Interestingly, it appears that the NF- $\kappa B$ inhibitorssuch as pyrrolidine dithiocarbamate (PDTC) increaseHO-1 mRNA and protein expression in human colon cancer HT29 cells(Min, Lee, Joe, \& Kwon, 2011).Recently, it has been reported1) a functional $\kappa B$ 
element in the mouse $\mathrm{HO}-1$ promoter and 2)that the NF-אB subunits $\mathrm{p} 50$ and $\mathrm{p} 65$ and the inducible NO-synthase mediated HO-1 up-regulation in vivo(Q. Li, et al., 2009).

\section{Nrf2}

The view of oxidative stress has broadened considerably. It is now often seen as an imbalance that has its origins in genes, and the ways in which gene expression is regulated. At the center of this field is the transcription factor called nuclear factor (erythroid-derived 2)-like 2, or Nrf2. Nrf2 is referred to as the "master regulator" of the antioxidant response, modulating the expression of hundreds of genes, including not only the familiar antioxidant enzymes, but large numbers of genes that control number processes such as immune and inflammatory responses(Hybertson, Gao, Bose, \& McCord, 2011). It is important to point out thatthe redox-dependent Nrf2 system plays a central role for $\mathrm{HO}-1$ induction in response to oxidative stress. There are several critical regulatory domains present in a 10-kb region of the 5'-flanking sequence of the HO-1 gene. Two of the most highly studied enhancer regions, called E1 and E2, contain stress-response elements (StRE) and structurally resemble the antioxidant response element (ARE).The major positive transcriptional regulator of $\mathrm{HO}-1$ gene acting on the StREs is represented by Nrf2. Nrf2 is ubiquitinated by forming a complex with the Kelch-like ECH-associated protein 1 (Keap1). Keap1 targets Nrf2 for ubiquitindependent degradation and, hence, represses Nrf2-dependent gene expression. Some HO-1 inducers or oxidative stress may prevent Keap1-dependent degradation of Nrf2, thereby resulting in Nrf2 nuclear accumulation. Accumulated or stabilized Nrf2 may bind to the StRE regions to form complexes with the small Maf proteins leading to initiation of HO-1 gene transcription (MacLeod, et al., 2009).In response to nitrosative stress, the activation of Nrf2 signaling led to the induction of $\mathrm{HO}-1$ as a protective mechanism against inflammatory damage. Stimulation with lipopolysaccharide (LPS) inducediNOS expression in both $\mathrm{Nrf2+/+}$ and Nrf2-/- macrophages, while HO-1 expression was only evident in Nrf2+/+ cells. The LPS induced iNOS expression was suppressed by pretreatment with $\mathrm{HO}-1$ inducers in $\mathrm{Nrf2+} /+$ macrophages(Ashino, et al., 2008).

\section{NO2-FA}

Recently, it has been reported the potential impact of electrophilic nitro-fatty acid derivative (NO2-FA) on modulating endothelial gene expression and function as a therapeutic strategy, 
with these species exhibiting anti-inflammatory cell signaling properties that up-regulateHO1 in the vasculature, inhibit VSMC proliferation and activatePPAR $\gamma$ through Nrf2-dependent and Nrf2-independent processes. These signaling actions are attributable to the electrophilic nature of NO2-FA(Khoo \& Freeman, 2010). The electrophile-dependent modulation of NF-KB function represents one of the best-defined mechanisms accounting for the antiinflammatory actions of lipid derive electrophiles.A complex mechanism of action for electrophile-dependent modulation of NF- $\mathrm{KB}$ signaling has emerged, wherein electrophiles act at multiple levels.Through, these mechanisms of NF-KB signaling inhibition, electrophilic lipids act as redox-derived anti-inflammatory mediators.

HO-1 expression and activity induced by NO2-FAs can exert broad protective effects within the vasculature that suppresses pro-oxidant and pro-inflammatory mediators(Khoo, et al., 2010).It has been reported that nitro-fatty acid induces HO-1 expression incultured endothelial cells and rat aortic segments (Wright, et al., 2006). It appears that OA-NO2 also increases HO-1 expression in VSMCs in vitro and throughout the endothelial and intimal cells of vessels in vivo. Finally, the activation of HO-1 expression is a central element of the response of tissues to metabolic and inflammatory stress, and thus is regulated by multiple transcription factors sensitive to functional changes induced by oxidative and electrophilic species. These transcription factors may act either synergisticallyor antagonistically to modulate HO-1 expression.These observations indicate that regulationof human $\mathrm{HO}-1$ expression by NO2-Fasrequires synergy between different transcription factors such as Nrf2/Keap1 or AP-1(Wright, et al., 2009).

\section{AP-1}

The AP-1 family of transcription factors consists of Jun family oncoproteins that homo- or hetero-dimerize with other members of the Jun or Fos protein families.Inducible gene expression via AP-1 has been shown to be involved in a diverse range of cellular responses including immunological and antioxidant stress responses. Similar to NF- $\kappa B, A P-1$ is upregulated by a wide variety of pro-oxidant and pro-inflammatory stimuli.Functional AP-1 sites, which mediated inducer-dependent gene expression of $\mathrm{HO}-1$, have been identified in the promoter regions of the human HO-1 genes(Hock, et al., 2007).Age-related differences in the activation of AP-1 have been shown to contribute to the age-dependent increase in vascular smooth muscle cells VSMCproliferation and migration. The signaling networks that 
modulate all the key changes in VSMC during the aging process such asAP-1 transcription factor is associated with the redox-regulation of HO-1(M. Li \& Fukagawa, 2010).

\section{Bach1}

It has been demonstrated that the transcription factor Bach1 (BTB and CNC homology 1, basicleucinezipper transcription factor 1 ), which inhibits oxidative stress-inducible genes, is a crucial negative regulator of oxidative stress- induced cellular senescence(Dohi, et al., 2008). Bach1 forms a heterodimer with the small Maf oncoproteins and binds to the Mafrecognition element (MARE) to inhibit target genes, including that encoding HO-1(Igarashi \& Sun, 2006). The transcription repressor Bach1 has been recognized to be a key regulator of the inducible HO-1 gene expression. The DNA binding activity of Bach-1 is negatively regulated by heme in vitro, and this may account for the substrate dependent activation of ho-1(Ogawa, et al., 2001).

Bach1 has initially been shown to repress HO-1 gene expression in the presence of lowlevels of intracellular heme. When intracellular heme levels are elevated, Bach1 changes its conformation and dissociates from the HO-1 promoter, allowing Nrf2 to bind to AREs and to activate HO-1 gene expression(Ogawa, et al., 2001). In conclusion, inactivation of Bach1 by heme or oxidative stresses results in detachment of Bach1 from DNA and export into the cytoplasm, which allows Nrf2 to access Maf-recognition elements to up-regulate HO1(Kaspar \& Jaiswal, 2010).

Recently, had beenexaminedin cardiac derived H9c2 myocytesexposed to different doxorubicinconcentrations, the interplay between oxidative stress, cell death in anthracycline-mediated cardiotoxicityand modulation of HO-1. The findings suggest that the down-modulation of HO-1 plays a role in the ROS-independent apoptosis triggered by exposure to low doses of doxorubicin andindicate a strong correlation between increased levels of Bach1and the down-regulation of HO-1 in apoptotic H9c2(Bernuzzi, Recalcati, Alberghini, \& Cairo, 2009).These results suggest thatDOX may facilitate the apoptosis of cardiomyocytes by inhibiting the anti-apoptotic HO- in correlation with increasing levels of Bach-1. In different fields, Bach-1 represents an important transcriptional repressor such as human leukemia(Miyazaki, et al., 2010) and atherosclerosis; disruption of the Bach1 gene in Apo E KO mice causinginhibition of atherosclerosis through up-regulation of HO-1(Watari, et al., 2008). 


\subsection{Signalingto COand biological "acceptors" of CO}

Surprisingly, CO can induce HO-1 expression, raising a possibility that $\mathrm{CO}$ may exert full effects not only through the first pathway associated with its original ability but also through the second pathway associated with HO-1 expression(B. S. Lee, et al., 2006). In this regard, CO may serve as an effective HO-1 inducer.

As we reported, CO exerts a variety of diverse effects in different tissues, and these can occur through modulation of multiple pathways. Many of the effects of $\mathrm{CO}$ depend on the activation of guanylate cyclase, which generates guanosine $3^{\prime}, 5^{\prime}-$-monophosphate (cGMP), and the modulation of mitogen-activated protein kinase (MAPK) signaling pathways $(\mathrm{H}$. P. Kim, et al., 2006). The biological "acceptors" of CO are structures containing transition metals, the best known of which is heme; the number of potential targets at which CO could act is large, heme-proteins being widely distributed.CO binds to a range of intracellular heme proteins, including the ferrous heme a3 of cytochrome c oxidase (Cyt a3), the terminal electron acceptor of the mitochondrial respiratory chain. Under anaerobic conditions, a molecule of $\mathrm{CO}$ binds to the reduced heme a3 instead of oxygen.In these conditions, $\mathrm{CO}$ appears as an important "regulator" of mitochondrial respiration(Lo lacono, et al., 2011). Mitochondria are involved in hematopoietic cell homeostasis through multiple ways such as oxidative phosphorylation, various metabolic processes and the release of cytochrome $c$ in the cytosol to trigger caspase activation and cell death(Fontenay, Cathelin, Amiot, Gyan, \& Solary, 2006). An important factor in the active mitochondrial biogenesis program initiated by $\mathrm{CO}$ is $\mathrm{HO}-1$ induction, supported in part by mitochondrial heme release(Cronje, Carraway, Freiberger, Suliman, \& Piantadosi, 2004). CO also stimulates mitochondrial biogenesis, which is activated in part when $\mathrm{CO}$ binds to cytochrome $\mathrm{c}$ oxidase and boosts mitochondrial hydrogen peroxide production.Mitochondrial biogenesis in various organs is activated by the gaseous signaling molecules NO and CO(Rhodes, et al., 2009).

Reviews highlight the fact that $\mathrm{CO}$ exerts a variety of diverse effects in different tissues, and these can occur through modulation of multiple pathways(Peers \& Steele, 2012).CO activates the heme protein SGC and so increases cyclic GMP levels. However, since its affinity 
for SGC beingconsiderably lower than that of NO, such an intracellulareffect is only important when NO levels are low.

The ability of CO to "mimic" NO in activating SGC is only one way in which CO can interfere with NO signaling: CO can also, in certain conditions,bind and activate NOS to stimulate NO production(Lim, et al., 2005). Experimental evidence suggests that CO modulates the generation of NO, and, by so doing, regulates vascular tone. But, it is important to note that the mechanisms by which the gases exert their actions depend of different factors: such as the different localizations of the NOs and HO enzymes. Although, number studies demonstrate the role of spatial relations among the gas-producing enzymes and their reception systems(Kajimura, et al., 2010).

CO can exert important influences on ROS levels and signaling in various tissue types. But,macrophages being a major cellular target of $\mathrm{CO}$, the majority of studies have focused on this cell type in the inflammatory response. By inducingmitochondrial ROS and in some cases RNS, CO rapidly conditions the macrophage gene expression,activation and enzymes activities.In this context, $\mathrm{CO}$ has been shown to inhibit NADPH oxidase in macrophages and airway smooth muscle cells(Taille, El-Benna, Lanone, Boczkowski, \& Motterlini, 2005).Enzymatic systems, such as the mitochondrial respiratory chain, NADPH oxidases and xanthine oxidase, increase the levels of superoxide in cells. Among them, NADPH oxidases had a critical role in influencing the redox balance in vasculature. Another potential source of $\mathrm{O}_{2}{ }^{--}$in vascular cells is what has been described as 'uncoupling of eNOS', a situation in which eNOS can generate superoxide when the concentrations of L-arginine or tetrahydrobiopterin $\left(\mathrm{BH}_{4}\right)$ are low. The sources of ROSmay be from the vascular NAD(P)H oxidases duringvascular injury, stem from ROS production by the influx of inflammatory cells.NADPH oxidases playimportant roles in pathological cardiovascular situations(Lauzier, Sicard, Bouchot, Delemasure, Menetrier, et al., 2007; Sicard, et al., 2007; Sicard, et al., 2008).Another site of $\mathrm{CO}$ binding is the cytoplasmic oxidases, i.e., the $\mathrm{P}_{450}$ cytochromes. It becomes increasingly apparent that exogenous $\mathrm{CO}$ exposure and the endogenous production of $\mathrm{CO}$ by $\mathrm{HO}$ favors a pro-oxidant milieu in aerobic mammalian cells that promotes ROS-dependent signaling, including the activation of redox-sensitive transcription factors(Piantadosi, 2008).

\subsection{Anti-inflammatory effects}




\section{Effects on immune competent cells}

CO exerts direct effects on immune competent cells(Hoetzel, Dolinay, Schmidt, Choi, \& Ryter, 2007). For instance, CO inhibits the activation of monocytes, macrophages, and leukocytes in vitro as well as in vivo. Furthermore, the ability of T cells to proliferate is suppressed by the application of CO. CO prevented the LPS-induced production of proinflammatory cytokines such as TNF- $\alpha$, IL1- $\beta$ and macrophage inflammatory protein- $\beta$ (MIP$1 \beta$ ) in cultured macrophages(Pae, et al., 2004). The inhibitory effects of CO on TNFalphaproduction were also demonstrated with the application of CORM-2 (Sawle, et al., 2005). CO treatment also promoted the increased production of the anti-inflammatory cytokine IL-10 during LPS challenge and the effect of IL-10 itself appeared to be mediated by $\mathrm{HO}$ activity and specifically required $\mathrm{CO}$ to exert its anti-inflammatory properties(Otterbein, et al., 2000).

\section{Induction of PPAR $\gamma$-SUMOylation}

Recent evidence indicates that $\mathrm{CO}$ exerts its anti-inflammatory effects through the induction of peroxisome proliferator-activated receptor (PPAR)-gamma, a nuclear receptor whose activation has been linked to several physiological pathways. In this context, it has been reported that CORM-2 and HO-1 induction significantly increase PPARs activation via ERK5 activation. Therefore, the induction of $\mathrm{HO}-1$ and subsequent activation of ERK5 is critical in up-regulating PPARs transcriptional activation as well as subsequent inhibition on inflammation(Woo, et al., 2006). It has beenreported thattreatment with CO (before LPS stimulation) increases expression of PPAR $\gamma$, in the nuclei of macrophages (Bilban, et al., 2006). It washypothesized that the ability of $\mathrm{CO}$ to cause a relatively low intensity oxidative burst from the mitochondria would lead to PPAR $\gamma$ activation. The effects of CO on PPAR $\gamma$ do not involve direct binding of $\mathrm{CO}$ to these proteins mainly because of the absence of heme as a prosthetic group(Bilban, et al., 2008).These findings show that exposure to CO leads to a burst of ROS from the mitochondria that directs the subsequent up-regulation of PPAR $\gamma$.

The protective effects of $\mathrm{CO}$ on apoptotic cell death have now been characterized in several cell types, including epithelial and endothelial cells. Several signaling pathways have been implicated in CO-dependent cytoprotection, including the p38MAPK, NF- $\mathrm{KB}$ 
pathways,soluble guanylate cyclase, and other transductionfactors. Recent studies indicate that COcan potentially accelerate the turnover of mitochondria by stimulating both mitochondrial degradation and biosynthesis pathways(S. J. Lee, et al., 2011).

Recent reports indicate that regulation of SUMO-conjugation contributes to the pathogenesis of inflammationand development of metabolic andcardiovascular diseases. SUMO (small ubiquitin-like modifier) covalently attaches to certain residues of specific target proteins and alters a number of different functions depending on the substrates. Recent studiesreported that some stimuliof PPAR 1 activity, via activation of ERK5, contributes to anti-inflammatory. A new mechanism of disease-inducedERK5-sumoylation is able toexplain the causal relationship between a metabolic disease such as diabetes andinflammation(Woo \& Abe, 2010). In a recent study, it had been identified a new mechanistic findings in this area.CO treatment resulted in mitochondria driven ROS-dependent SUMOylation of PPAR $\gamma$ and UCP2; this effectbeing in part responsible for ROS generation by CO. Additionally, using $\mathrm{N}$-acetylcysteine, to selectively scavenge ROS, including superoxide and peroxides, itwas demonstrated that PPAR $\gamma$-SUMOylation is contingent upon CO-induced ROS formation(Haschemi, et al., 2011).

\section{The immune-modulatory role of $\mathrm{HO}-1$ and $\mathrm{CO}$}

The immune-modulatory role of $\mathrm{HO}-1$ and $\mathrm{CO}$ has received a great deal of attention in recent years because of its potent anti-inflammatory functions. Emerging evidence suggests that toll-like receptors (TLRs) that play important roles in initiation of innate and adaptive immune responses are implicated in the potent anti-inflammatory functions of CO and CORMs.It has been demonstrated that CO suppresses TLR-4 signaling(X. M. Wang, Kim, Nakahira, Ryter, \& Choi, 2009) and blocks the LPS-mediated induction of pro-inflammatory cytokines by modulation of the MAPK pathway. A potential link between HO-1 and inflammation has initially been shown in an animal model, in which specific up-regulation of HO enzyme activity attenuated complement-dependent inflammation and targeted overexpression of HO-1 has been shown to have beneficial effects in various experimental animal models of inflammation (Soares, Marguti, Cunha, \& Larsen, 2009; Willis, Moore, Frederick, \& Willoughby, 1996). Therefore, identification and characterization of pharmacological compounds that induce HO-1 in a cell-specific and cell context specific manner deserve further attention (Paine, Eiz-Vesper, Blasczyk, \& Immenschuh, 2010). HO-1 
appears as molecule of high significance in the protection against innate and adaptive immune aberrations. Recent data support the presence of an additional direct effect of myeloid HO-1 on innate immune conditioning. In myeloid cells, HO-1 forms a complex with the transcription factor interferon regulating factor 3 (IRF3) and is required for IRF3 phosphorylation and consequent type-I interferon and chemokine gene induction (Koliaraki \& Kollias, 2011). Finally, enhanced HO-1 expression or the pharmacological application of HO end-products affords protection in preclinical models of tissue injury, including experimental and transplant-associated ischemia-reperfusion injury, promising potential future therapeutic applications (Morse, et al., 2009).

Recent findings reveal a multifaceted role for $\mathrm{HO}-1$ in immune responses in response to bacterial or viral stimuli; HO-1 is required for early activation of the typelFN-inducing pathway and subsequent development of antiviral or adaptive immunity. At a later time point, HO-1, through CO production, acts to inhibit the pro-inflammatory response and enhance the anti-inflammatory effects of IL-10(Tzima, Victoratos, Kranidioti, Alexiou, \& Kollias, 2009).

Macrophages are key innate immune effector cells best known for their role as phagocytes.These cells respond to many different types of foreign and host-derived stimuli with responses referred as activation $\mathrm{M} 1$ or $\mathrm{M} 2$. Interestingly, dietary fatty acids are able to polarize macrophages towards M1 or M2states, depending on the signaling molecules with which they interact, thus providing a molecular basis for the cross-talk between metabolic and inflammatory pathways(Bhargava \& Lee, 2012).The HO-1 reaction products will be capable of blocking innate and adaptive immune responses by modifying the activation, differentiation, maturation, and/or polarization of immune cells, including dendritic cells(Durante, 2012). In the heart, it wasrecently reporteddendritic cell infiltration in the infarcted myocardium suggestingthat dendritic cell is a potent immune-protective regulator during the post-infarction healing process, via controlling monocyte/macrophage homeostasis(Anzai, et al., 2012).

\subsection{CO: regulator of ion channels}

$\mathrm{CO}$ is emerging as an important cellular messenger, regulating a wide range of physiological and pathologicalactions.Its role is to regulate several classes of ion channels, including 
calcium-activated- $\mathrm{K}^{+}(\mathrm{BK}(\mathrm{Ca}))$, voltage-activated- $\mathrm{K}^{+}(\mathrm{K}(\mathrm{v}))$ and $\mathrm{Ca}^{2+}$-channel (L-type) families, ligand-gated P2X receptors (P2X2 and P2X4), tandem P domain $\mathrm{K}^{+}$channels (TREK1) and the epithelial $\mathrm{Na}^{+}$channel $(\mathrm{ENaC})$. The mechanisms by which $\mathrm{CO}$ regulates these ion channels are still unclear(Wilkinson \& Kemp, 2011).An action site of CO, which has been characterizedin porcine arteriolar smooth muscle cells, is a direct cGMP-independent activation of $\mathrm{K}^{+}$ channels leading to a hyperpolarisation of the membrane(Kanu \& Leffler, 2007). Another interaction known with ion channels is the cGMP-independent inhibition of $\mathrm{Na}^{+}$channels in alveolar epithelium(Althaus, et al., 2009).It has been demonstrated that activation of $\mathrm{KCa}$ channels mediates CO-induced vasorelaxation. The activation of large conductance $\mathrm{KCa}$ channels in SMCs accounts for a significant part of the relaxation induced by CO. Paradoxically, the KCa channel-mediated vasorelaxing effect of $\mathrm{CO}$ was significantly decreased approximately $40 \%$ in the presence of sodium nitroprusside, a donor of NO.These results indicated that NO might desensitize $\mathrm{KCa}$ channels toward CO.The nature of the interaction between $\mathrm{NO}$ and $\mathrm{CO}$ on $\mathrm{KCa}$ channels is complex.These $\mathrm{KCa}$ channels are composed of two non-covalently linked subunits: the poreforming $\alpha$-subunit and the accessory $\beta$-subunit, which affects the electrophysiological and pharmacological properties of KCa channel organization(L. Wu, Cao, Lu, \& Wang, 2002). The interactions of CO with $\alpha$ and $\beta$-subunits of KCa channels may be the determining factor for the selective modulation of KCa channels.

Recent studies report that CO inhibited both native cardiac KCa channels and the $\alpha 1 \mathrm{C}$ subunit of theL-type voltage-gated calcium channel (Cav1.2)expressed alone in HEK 293 cells. These effects of $\mathrm{CO}$ mimicked by the CORM-2, were insensitive to manipulation of the sGC-cGMP-protein kinase G pathway, but were prevented by antioxidants, implicating ROS as mediators of these effects(Peers, 2011).ROS induce apoptosis in cells. An early step in this process is the loss of intracellular $\mathrm{K}^{+}$via $\mathrm{K}^{+}$channels. Recent works have demonstrated that many ion channels can themselves directly influence biochemical events in ways that do not directly depend on their function as ion channels.Among the cellular behaviors that voltagegated potassium (Kv) channels regulate independently of their conducting functions are $\mathrm{Kv}$ channel: Kv2.1.It is reported recently that Kv2.1 is of particular importance in pathophysiology, being rapidly inserted into the plasma membrane in response to apoptotic stimuli. An additional feature of oxidative stress is the up-regulation of the inducible HO-1. COprovides marked protection against oxidant-induced apoptosis; this effect being 
associated with reversibly inhibition of Kv2.1. Overexpression of Kv2.1 in HEK293 cells increases their vulnerability to oxidant induced apoptosis, and this is reversed by CO(Dallas, et al., 2011). These findings suggest that the inhibition of Kv2.1 by CO may be a pathway for potential therapeutic exploitation to prevent or suppress cell damage.

\section{Dysregulation, disease and potential therapeutic use of CO and CORMs}

\subsection{Cardiovascular disorders}

CO-releasing molecules (CO-RMs) and CO gas

The development of a technology that controls the delivery of CO under different physiological conditions represents a major step in the use of CO-RMs. There is an abundance of preclinical evidence in experimental studies showing the beneficial effects of CO, administered as a gas or as a CO-RM, in cardiovascular disease(Motterlini, 2007; Ryter, et al., 2006).CORM-3 and CORM-A1 represent the examples of water-soluble CO releasers (Figure 2).As we reported previously, the two compounds are fundamentally different in terms of chemical structure and rate of CO liberation: CORM-3 is a ruthenium-based tricarbonyl complex with a fast CO release $\left(t_{1 / 2}<1 \mathrm{~min}\right)$, whereas CORM-A1 is a boroncontaining carboxylic acid that under physiological conditions releases $\mathrm{CO}$ with a slow kinetic $\left(t_{1 / 2}=21 \mathrm{~min}\right)$. This chemical difference dictates the way CO causes vasorelaxation and hypotension since CORM-3 elicits a prompt and rapid vasodilatory effect whereas CORM-A1 promotes mild vasorelaxation and hypotension. In addition, CORM-3 induced vasorelaxation appears to be primarily cGMP- and endothelium-dependent; in contrast, the vasodilatory effect mediated by CO slowly liberated from CORM-A1 involves guanylate cyclase and potassium channel activation but appears to be endothelium-independent(Motterlini \& Otterbein, 2010). Moreover, while CORM-1 requires light to liberate CO, CORM-2 spontaneously releases $\mathrm{CO}$ once in contact with myoglobin or other heme-dependent proteins that trigger the dissociation of $\mathrm{CO}$ from the metal. $\mathrm{CO}$ is important for the homeostatic control of cardiovascular functions. Vascular disease is perhaps the most logical arena for which CO would provide protective effects simply due to the mode of delivery, 
which probably involves offloading from hemoglobin directly to the endothelium and smooth muscle.

Both $\mathrm{HO}-1$ and $\mathrm{HO}-2$ contribute to the endogenous production of $\mathrm{CO}$ in the cardiovascular system(Chan, Ng, \& Stocker, 2011). HO-2 expressed in endothelial and smooth muscle layers of arterial and venous blood vessels has been reported to generate CO that intrinsically modulates vascular tone. Depending on the types of blood vessels, $\mathrm{HO}-2$ may become critical in regulating the production of carbon monoxide and vascular tone.

Abnormal metabolism and function of $\mathrm{CO}$ contributes to the pathogenesis and development of hypertension(Ndisang, Tabien, \& Wang, 2004). Correction of these abnormalities in the $\mathrm{HO} / \mathrm{CO}$ system would be beneficial for the prognosis of hypertension. This has been demonstrated in SHRs and other types of model of hypertension(Mustafa \& Johns, 2001) such as DOCA-salt, phenylepherine- and angiotensin II-induced hypertension(Aizawa, et al., 2000). Hypertension is characterized by increased vascular contractility, concomitant increase in oxidative stress, enhanced vascular inflammation and vascular remodeling. An up-regulated $\mathrm{HO} / \mathrm{CO}$ system would not only normalize the endogenous $\mathrm{CO}$ concentration, but also increase the production of biliverdin and bilirubin, two potent antioxidants. Increased production of $\mathrm{CO}$ can suppress the progress of abnormal vascular contractility and vascular remodeling. Anti-inflammatory and antioxidant protection of cardiovascular tissues will also protect against both the primary and secondary damage inflicted on tissues by hypertension.

In a mouse myocardial infarct model by coronary artery occlusion, intravenous infusion of CO-RM3 before reperfusion reduced infarct size, fibrillation and tachycardia(Clark, et al., 2003; Lo lacono, et al., 2011; Varadi, et al., 2007). These cardioprotective mechanisms mediated by Co-RMs probably involve potassium channels. BKCa channels are also important in several physiological phenomena, including oxygen sensing and vasodilatation. Although potassium channels do not normally contain a transition metal, heme-protein complexes can be formed in the BKCa complex.

The vasoconstrictor and vasodilatory responses to $\mathrm{CO}$ are critically conditioned by redox mechanisms. The vasoconstrictor action is linked to increased oxidant activity which 
promotes formation of isoprostanes. The vasodilatory action is linked to mechanisms involving SGC and KCa channel, and requires conditions that offset the pro-oxidant activity of CO (Figure 4).

It may be anticipated that acute administration of $\mathrm{CO}$ would elicit vasodilatation, because biliverdin/bilirubin would be present when redox balance is in equilibrium; however, the present studies were conducted in an isolated, non-blood perfused system. Plasma bilirubin has been shown to have a large capacity to combat oxidative stress; therefore, lack of this pigment may reduce the antioxidant capacity of the vessel wall and allow for CO to elicit vasoconstriction. Therefore, the effects of CO may be largely dependent on environmental redox balance or, in some cases, experimental conditions.

The debate as to whether $\mathrm{CO}$ of vascular origin functions as a vasodilator or vasoconstrictor has been fueled by conflicting reports in the literature. The mechanism associated with COinduced vasoconstriction, which appears to involve the generation of $\mathrm{O}_{2}{ }^{\bullet-}$ and potentially downstream ROS, has not been elucidated to date. ROS are known to lead to the generation of non-enzymatic metabolites of arachidonic acid known as isoprostanes that are capable of constricting vessels.

The cellular and molecular mechanisms responsible for the vasorelaxant effects of $\mathrm{CO}$ at physiologically relevant concentrations are not restricted to GC activation. CO directly enhances the activity of big-conductance calcium-activated potassium channels $\left(\mathrm{BK}_{\mathrm{Ca}}\right)$ in rat vascular smooth muscle cells through a cGMP-independent mechanism. The opening of $\mathrm{BK}_{\mathrm{Ca}}$ channels leads to membrane hyperpolarization, which in turn closes voltage-dependent calcium channels, reduces resting calcium concentration and ultimately relaxes vascular tissues.

\subsection{Lung and pulmonary arterial hypertension}

The lungs are a major target for various inflammatory, oxidative, carcinogenic or infectious stressors, which result in a range of lung diseases. Induction of HO-1 during acute and chronic lung processes is an important defense mechanism(Raval \& Lee, 2010). The HO-1 system is a powerful endogenous defense strategy with immense therapeutic potential against a range of lung diseases(Fredenburgh, Perrella, \& Mitsialis, 2007). Many chronic 
pulmonary diseases are associated with pulmonary hypertension and pulmonary vascular remodeling.Pulmonary arterial hypertension is driven by an increased expansion of vascular smooth muscle in the pulmonary arterioles and leads to right heart hypertrophy and infarct(Ecarnot-Laubriet, et al., 2002; Ecarnot-Laubriet, et al., 2000). In rodent models of established pulmonary arterial hypertension, inhaled CO restored thickened pulmonary arteries and the right heart to normal size and pressures by a mechanism involving endothelial-derived NO to induce apoptosis of the hyperproliferative vascular smooth muscle cells(Zuckerbraun, et al., 2006). Important results had been reported in which CO prevents intimal hyperplasia by arresting hyperproliferative vascular smooth muscle cells and increased mobilization and recruitment of bone-narrow-derived progenitor cells(Wegiel, et al., 2010). Therefore promoting re-endothelialization after vascular intervention is an important target. The final broad category of effects of $\mathrm{CO}$ is its ability to influence cellular proliferation. CO blocks the proliferation of a large variety of cells:cancer cells, effector T cells, hyperproliferative smooth muscle cells of hyperplastic intima following vessel trauma, as well as chronic vascular remodeling in pulmonary hypertension. Pulmonary ischemiareperfusion caused by temporal clamping of the pulmonary artery induced the biochemical features of apoptosis in experimental rodent lungs. The protective effect of CO pretreatment on mice subjected to lung ischemia-reperfusion in vivo was associated with caspase-3 activation and depended on activation of p38 MAPK, markers of apoptosis(X. Zhang, et al., 2003; X. Zhang, Shan, Alam, Fu, \& Lee, 2005).

\subsection{Organ transplantation}

One of the best studied models of I/R injury is organ transplantation(Lauzier, et al., 2008; Lauzier, Sicard, Bouchot, Delemasure, Menetrier, et al., 2007).Generally, these models involve cold preservation of organs followed by warm reperfusion of the grafts. The transplanted organs are therefore at risk of injury during both the preservation and the reperfusion phases(Lauzier, et al., 2009). The involvement of HO-1 in chronic graft dysfunction due to immunologic rejection has also been well studied. Currently used cold storage procedures can limit but not completely avoid ischemic injury and graft dysfunction in patients receiving transplants. $\mathrm{CO}$, either as a gas (saturated solution) or in the form or CO-RMs, can act as protective adjuvants of the preservation solutions. 
Transplantation has been certainly the field of study in which most studies has been made concerning the beneficial properties of CO-releasing molecules.CO has been evaluated in every transplantable organ system as well as isletsand shown beneficial effects by treating the donor, the organ or the recipient(Akamatsu, et al., 2004).

Data provide evidence that HO-1 is involved in the complex pathologies of organ transplantation. As we reported in this review, degradation of heme by $\mathrm{HO}-1$ yields multiple compounds: $\mathrm{CO}, \mathrm{Fe}^{++}$that leads to up-regulation of ferritin and biliverdin. These products are antioxidants. It is hypothesized that HO-1 activity can interfere directly and indirectly with processes that are involved in transplantation.

A recent report(B. Chen, et al., 2009) showed that aortic transplantation in HO-1-deficient mice results in $100 \%$ mortality within 4 days owing to severe arterial thrombosis. Notably, treatment of HO-1-deficient mice with CO-RM2 improved survival (62\% survival at > 56 days). Interestingly, histological analyses showed that CO-RM2 treatment markedly reduced platelet aggregation in the graft, confirming previous data on the anti-aggregatory properties of $\mathrm{CO}-\mathrm{RM} 3$ and $\mathrm{CO}$ gas and emphasizing the pleiotropic properties of these compounds in the resolution of vascular disorders(Chlopicki, Olszanecki, Marcinkiewicz, Lomnicka, \& Motterlini, 2006).

Several experimental approaches have been made to induce HO-1 in the donor (non-brain dead) to improve outcome with respect to early and long-term graft function. Induction of HO-1 in the donor is beneficial in many islet and xeno-transplantations(Ollinger \& Pratschke, 2010). Beneficial effects of HO-1 modulation have been described in xeno-transplantation models(Sato, et al., 2001) where HO-1 gene expression appears functionally associated with xenograft survival. In a mouse-to-rat heart transplant model, the effects of HO-1 upregulation could be mimicked by $\mathrm{CO}$ administration, suggesting that $\mathrm{HO}$-derived $\mathrm{CO}$ suppressed the graft rejection. The authors proposed that $\mathrm{CO}$ suppressed graft rejection by different process such as inhibition of platelet aggregation. The ability of $\mathrm{CO}$ to suppress inflammation is likely involved in xenograft transplant models in which 400 ppm CO for 2 days prevented rejection for up to 50 days. One other example for which CO-RM3 have proved effective in organ transplantation were reported(Bagul, Hosgood, Kaushik, \& Nicholson, 2008)(Bagul, et al., 2008). In an experimental model of non-heart-beating donor kidney in pigs, low concentrations of CO-RM3 ameliorated a loss in renal blood and urine flow.The modulatory effects of $\mathrm{CO}$ on platelet aggregation, vasodilation and pro- 
inflammatory cytokines all potentially contribute to the favorable outcome in xenograft transplantation. Donor and recipient HO-1 polymorphism may have an influence on longterm graft function (Ozaki, et al., 2008).Additionally, the correlation of HO-1 gene polymorphisms and the efficacy of immuno-suppressants have been studied (Yamashita, et al., 2006).

Effects of $\mathrm{CO}$ on the liver have been investigated in models of inflammation- and ischemia/reperfusion-induced hepatocellular injury. In cold ischemia reperfusion associatedwith liver transplantation, $\mathrm{CO}$ inhalation suppressed the inflammatory response. Down-regulation of MEK/ERK1/2 seems to play a role in mediating the protective effects while the NF-KB signaling pathway is not affected(Kaizu, et al., 2008). In models of liver ischemia and reperfusion, $\mathrm{HO}-1$ induction plays an important role in maintaining hepatocellular integrity and induction of $\mathrm{HO}-1$ before ischemia can attenuate the subsequent hepatic injury. Recentfindings suggest that CO-RM could be utilized as adjuvant therapeutics in University of Wisconsin (UW) solution to limit the injury sustained by donor livers during cold storage prior to transplantation(Pizarro, et al., 2009; Schmidt, et al., 2007). Clearly, HO-1 via CO and products of heme degradation, exerts a dual function in transplantation 1 ) by preventing oxidative stress 2 ) via anti-inflammatory mechanisms.

\subsection{Liver}

The liver plays a crucial role(Puntarulo, 2005) for the body's iron homeostasis (eg. via secretion of the iron regulatory hormone hepcidin) and also for systemic inflammation. Hepatic HO-1 may be important for the regulation of both systems. It has been reported anendogenous hepatic production of $\mathrm{CO}$ as $0.5-0.7 \mathrm{nmol} / \mathrm{mg}$ protein $/ \mathrm{g}$ tissue(Kajimura, Goda, \& Suematsu, 2002). During liver regeneration in vivo, CO and NO are supposed to play a significant role. $\mathrm{CO}$ is rapidly produced after partial hepatectomythrough induction of HO-1(Schuett, Eipel, Maletzki, Menger, \& Vollmar, 2007).The adult ho-1(-/-) mice developed an anemia associated with low serum iron levels, increased serum ferritin levels, and irondeposits in hepatocytes. These mice were more vulnerable to mortality and hepatic necrosis when challenged with endotoxin, indicating that the induction of HO-1 in liverrepresentsa defense mechanism to protect cells from oxidative damage(M. Bauer \& 
Bauer, 2002). CO is organ protective and counteracts hepatocyte apoptosis in vitro(Choi, Pae, Kim, \& Chung, 2003). A role of CO as a growth-promoting signal in the hepatocyte proliferation cascade is supported by findings that both overexpression of $\mathrm{HO}-1$ and cell exposure to CORM-2-derived CO accelerated hepatocyte growth(Krause, et al., 2010).

Serendipitous observation in metabolome analysis in CO-overproducing livers suggested roles of cystathioninebeta-synthase (CBS) that rate-limits trans-sulfuration pathway and $\mathrm{H}_{2} \mathrm{~S}$ generation, for the gas-responsive receptor(Shintani, et al., 2009). These results suggested that $\mathrm{CBS}$ serves as a $\mathrm{CO}$-sensitive modulator of $\mathrm{H}_{2} \mathrm{~S}$ to support biliary excretion. In the liver, the different gaseous mediators constitute an intriguing link for regulation of organ functions. 


\subsection{Inflammation and sepsis}

The anti-inflammatory properties of $\mathrm{CO}$ and $\mathrm{CO}-\mathrm{RMs}$ have been corroborated in a multitude of animal models of inflammation, suggesting a possible therapeutic application for inflammatory diseases. Increased accumulation of neutrophils, expression of intercellular

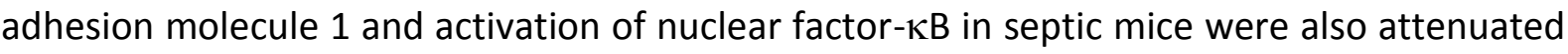
by systemic administration of CO-RM2, an effect that seems to be associated with decreased production of ROS and NO. Among the various inflammatory-related disorders, rheumatoid arthritis and osteoarthritis have recently received attention as potential clinical indications whereby the use of $\mathrm{CO}$ could be therapeutically effective.The CO-releasing molecule CORM3 protects against articular degradation in the K/BxN serum transfer arthritis model(Maicas, et al., 2010).

Similar anti-inflammatory effects of $\mathrm{CO}$ have now been demonstrated in models of I/R injury of the heart andkidney. CO protected against liver I/R injury via activation of the p38 MAPK(Amersi, et al., 2002). Homozygous ho-1 null mice (hmox-1 $1^{-1}$ ) displayed increased mortality in a model of lung I/R injury. Inhalation of CO (1,000 ppm) partially compensated for the HO-1 deficiency in $h m o x-1^{-l}$ mice, and improved survival following I/R (Fujita, et al., 2001). In this model, the authors propose that the protection provided by CO involved the enhancement of fibrinolysis, via the cGMP-dependent inhibition of plasminogen activator inhibitor-1 expression. Mice treated with a guanylate cyclase inhibitor, ODQ, were not rescued by CO from I/R-induced lethality. The second category of effects of CO encompasses broad effects on apoptosis. In endothelial cells, hepatocytes and cardiomyocytes, CO is antiapoptotic, preventing cell and tissue injury, whereas, in smooth muscle cells, cancer cells or fibroblasts, CO imparts pro-apoptotic effects (Brouard, et al., 2000; Z. Zhou, et al., 2005).The molecular mechanisms associated with apoptosis and which are modulated by $\mathrm{CO}$ exposure are still not fully understood. The protective effects of exogenous CO or CORMs may strongly depend on thetarget cell andtheconditions of application(I. Bauer \& Pannen, 2009).

Sepsis-induced death associated with Enterococcus faecalis infection in mice is also reversed by treatment with CO-RM2 in wild-type and HO1-deficient animals(Chung, Liu, Macias, Baron, \& Perrella, 2008)(Chung, et al., 2008). Recent findings report the possible applications of $\mathrm{CO}$ and CO-releasing molecules in acute lung injury and acute respiratory distress 
syndrome (ARDS)(Ryter \& Choi, 2010). Recent studies have explored the protective effect of $\mathrm{CO}$ and CO-RMs in vitro and in vivo in several models of ARDS. Despites therapeutic benefit in animal models studies, the efficacy of $\mathrm{CO}$ in humans remains unclear.Another important field of clinical protection is the hemorrhagic shock and resuscitation. The insult from severe hemorrhage is a multifactorial injury involving ischemia/reperfusion with inflammatory dysfunction. It has been demonstrated that the administration of exogenous $\mathrm{CO}$ at low concentrations provides cytoprotection in vivo and in vitro(Zuckerbraun, et al., 2005).

\section{Summary and future direction}

There are still a number of questions that remain to be answered, especially in relation to the interactions between the gases such as $\mathrm{CO}$ and $\mathrm{NO}$ or $\mathrm{H}_{2} \mathrm{~S}$. For instance, the exact correlation between these gases in the various pathways of cytoprotection has yet to be fully investigated(Kajimura, et al., 2010).

$\mathrm{CO}$ and CO-RMs exhibit a wide range of biological effects resulting in specific responses that involve a restricted number of intracellular pathways and targets that encompass inflammation, apoptosis and cellular proliferation. However, the effects of $\mathrm{CO}$ may be largely dependent on environmental redox balance or, in some cases, experimental conditions. Both CO gas and CO-RMs have potent anti-inflammatory effects with incidence on oxidative stress; they are able to decrease the production on inflammatory mediators and to attenuate the levels of NO and TNF- $\alpha$. Concerning the importance of HOs, a question that arises with regard to $\mathrm{HO}-1$ is whether $\mathrm{CO}$ generated endogenously during $\mathrm{HO}-1$ activity similar in concentrations to that administered exogenously by $\mathrm{CO}$ gas or by a CO-RM. Despite the corroborating evidence showing a crucial role for $\mathrm{HO}-1$-derived $\mathrm{CO}$ as a protective agent, the therapeutic concentrations may be extremely different. This is a challenging issue to resolve the biodynamic of HO1-derived $\mathrm{CO}$, its localization in distinct intracellular compartments and also the kinetics of $\mathrm{HO} 1$ induction.

It is becoming clear that the next major challenge surrounding the clinical applicability of the HO-1 system is to identify the particular disease states that will respond positively to altered HO-1 activity. Three therapeutic strategies exist: 1) pre-induction of HO-1 before a known injurious insult; 2) pre-treatment; and/or 3) post-treatment with exogenous byproducts of 
the HO pathway such as CO. And the other hand, as with all new agents, therapeutic strategies to minimize potential toxic effects are the ultimate objectives, and in this respect CO-RMs and inhaled CO are not any different. One fundamental challenge, however, for which development of the gas versus the CO-RMs differs, is in the parent molecule of the CO-RM. CO gas is simple, relatively non-reactive and easy to administer, with well-described pharmacodynamics and pharmacokinetics. Despites therapeutic benefit in animal models studies, the efficacy of $\mathrm{CO}$ in humans remains unclear. Further studies are expected to lead to a better understanding of the pharmacokinetics, and long- and short-term effects of the carbon monoxide-releasing compounds. 


\section{Acknowledgments:}

The authors thank Martine Goiset for secretarial assistance.

This work was supported by grants from the French Ministry of Research, from the Regional Council of Burgundy and from the Association de Cardiologie de Bourgogne. 


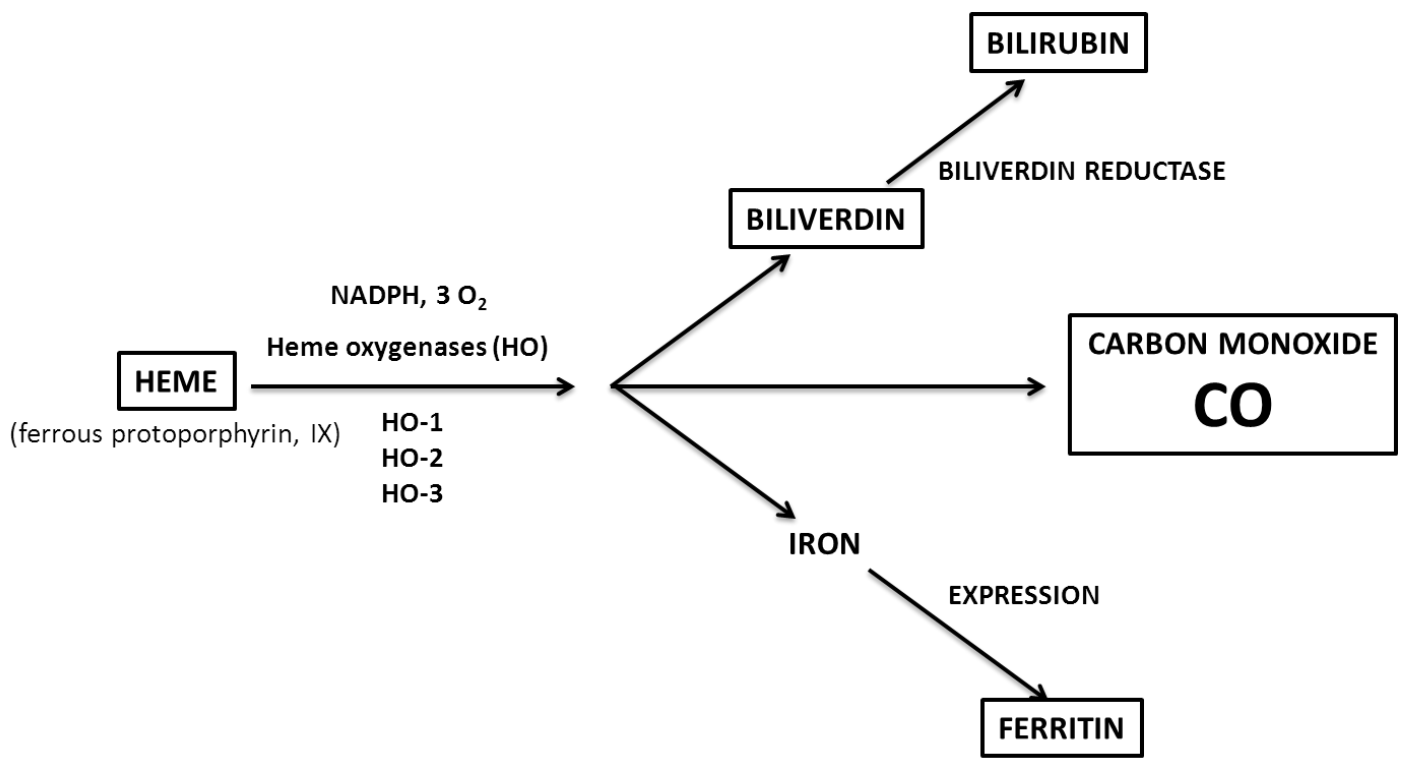

Figure 1

The heme degradation pathway. Heme is catalyzed into biliverdin by heme oxygenase ( $\mathrm{HO}-1,2$ and 3 ) with the release of a molecule of carbon monoxide ( $\mathrm{CO}$ ) and iron. Biliverdin is rapidly converted to bilirubin by a biliverdin reductase. Labile iron is pro-oxidant and can be "neutralized" by ferritin. 


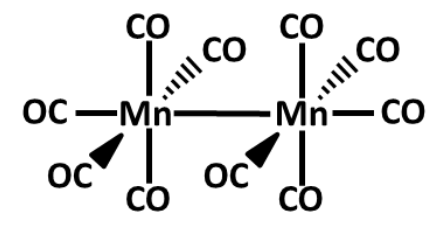

CO-RM1

Lipid soluble

"Fast" CO releaser

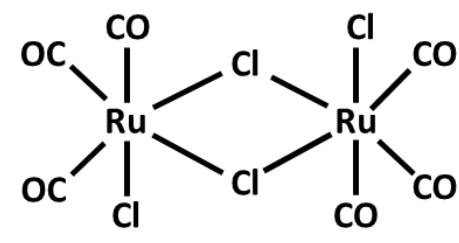

CO-RM2

Lipid soluble

"Fast" CO releaser

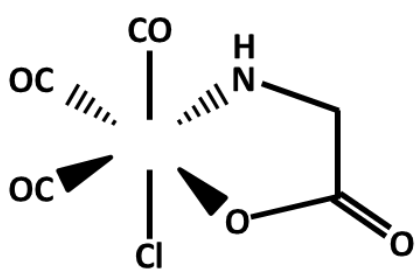

CO-RM3

Water soluble

"Fast" co releaser

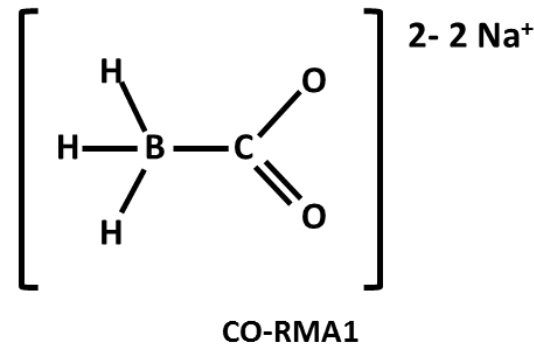

Water soluble

"Slow" CO releaser<smiles></smiles>

Photoactive CO-RM

$\left[\mathrm{Mn}(\mathrm{pqa})(\mathrm{CO})_{3}\right]\left(\mathrm{ClO}_{4}\right)$

pqa : 2-pyridilmethyl (2-quinolylmethyl) amine

Figure 2

Chemical structure of lipid-soluble, water-soluble and photoactive CO-RMs 
A

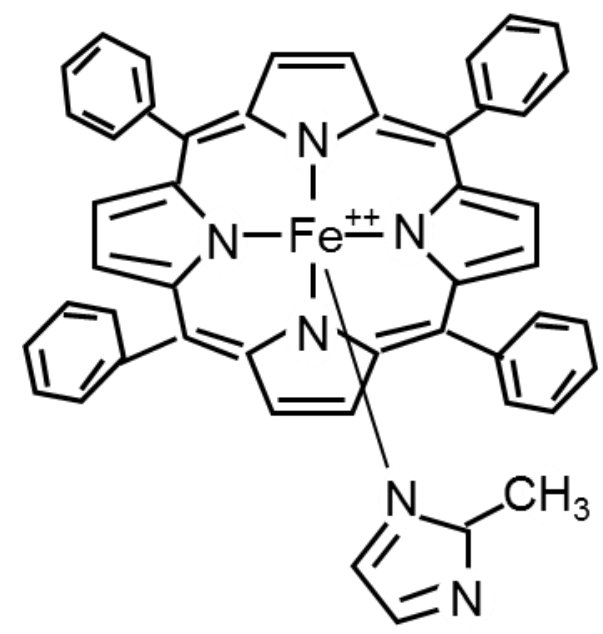

B

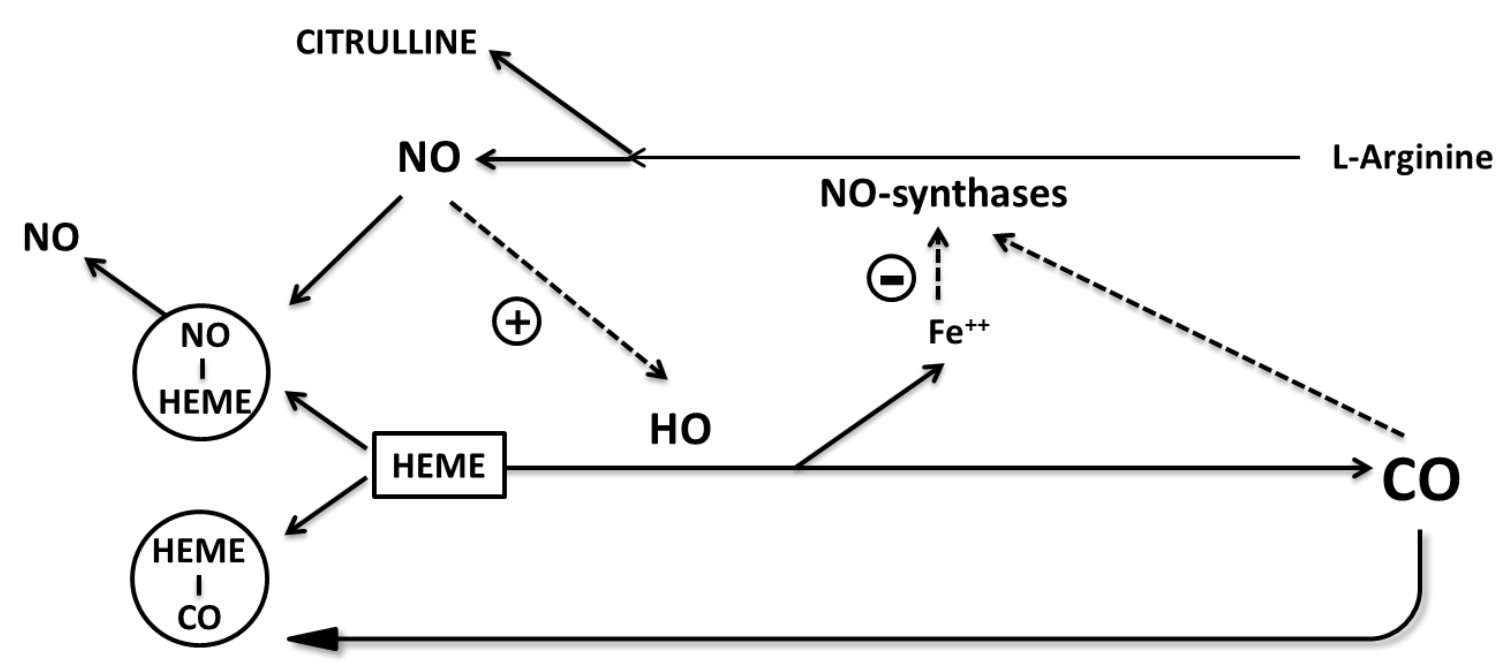

Figure 3

A: Chemical structure of Heme.

B: Interactions between NO and $\mathrm{CO}$. $\mathrm{CO}$ and NO are generated by endogenous enzymatic systems: heme oxygenases (HOs) and NOsynthases. Considering heme of hemoglobin ( $\mathrm{Hb})$, the affinity of NO for $\mathrm{Fe}(\mathrm{II})$ is 1,500 times greater than $\mathrm{CO}$. CO can stimulate NO release from proteins. "Free" iron acts as a pro-oxidant component inhibiting NO-synthases activities. $\mathrm{CO}$ competes against $\mathrm{O}_{2}$ for binding to the four heme iron centers of hemoglobin and forms carboxy-hemoglobin (CO-Hb). 


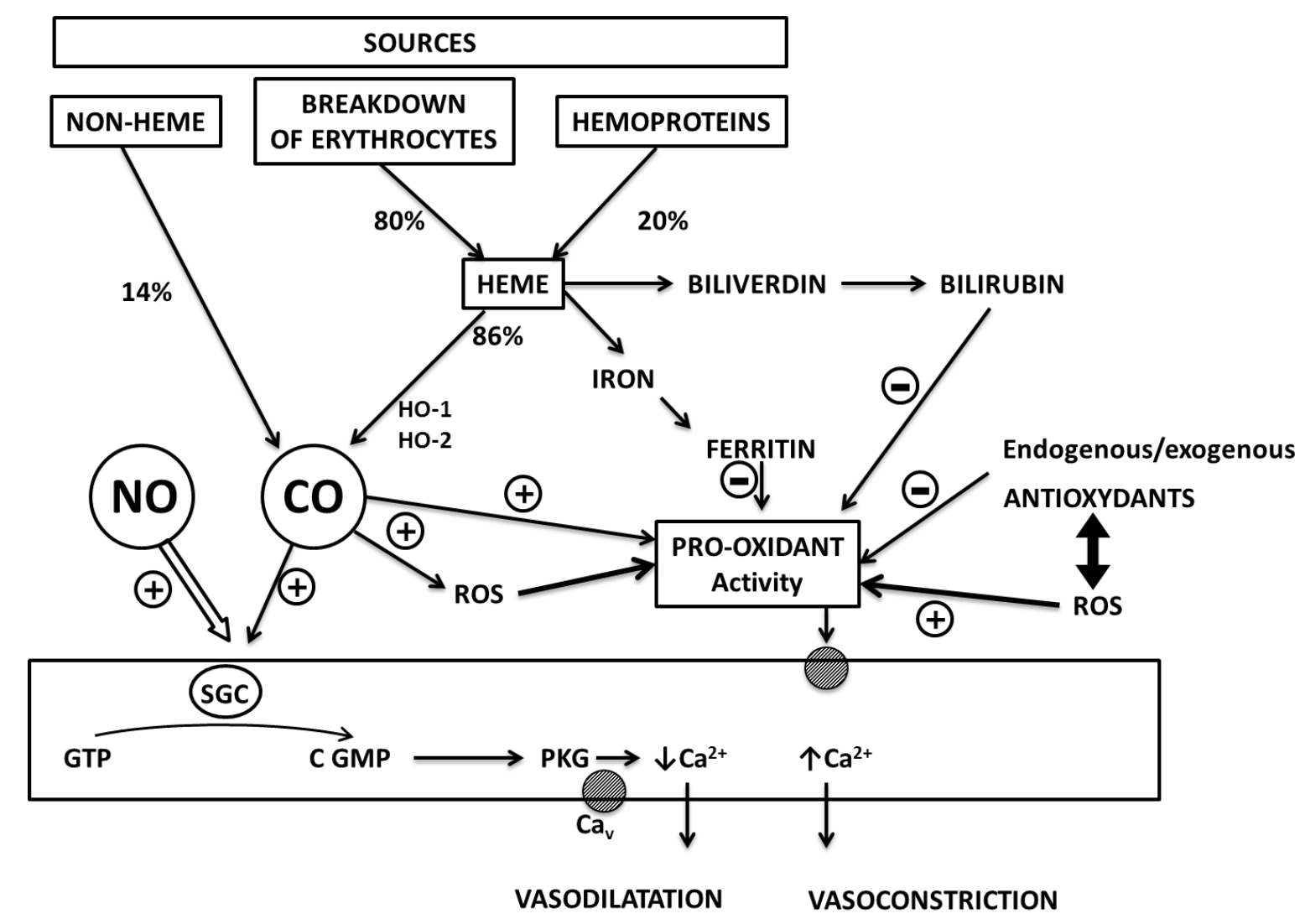

Figure 4

A major source of endogenous $\mathrm{CO}$ arises from the degradation of erythrocytes and hemoproteins. Equimolar $\mathrm{CO}$, iron and biliverdin are produced by $\mathrm{HO}$ enzymatic activity. The soluble guanylate cyclase (sGC) /cyclic 3':5'-guanosine monophosphate (cGMP) pathway and protein kinase-G (PKG) had been implicated in mediating the effects of $\mathrm{CO}$ on vasodilatation; vasoconstriction beingmediated via pro-oxidant agents. 


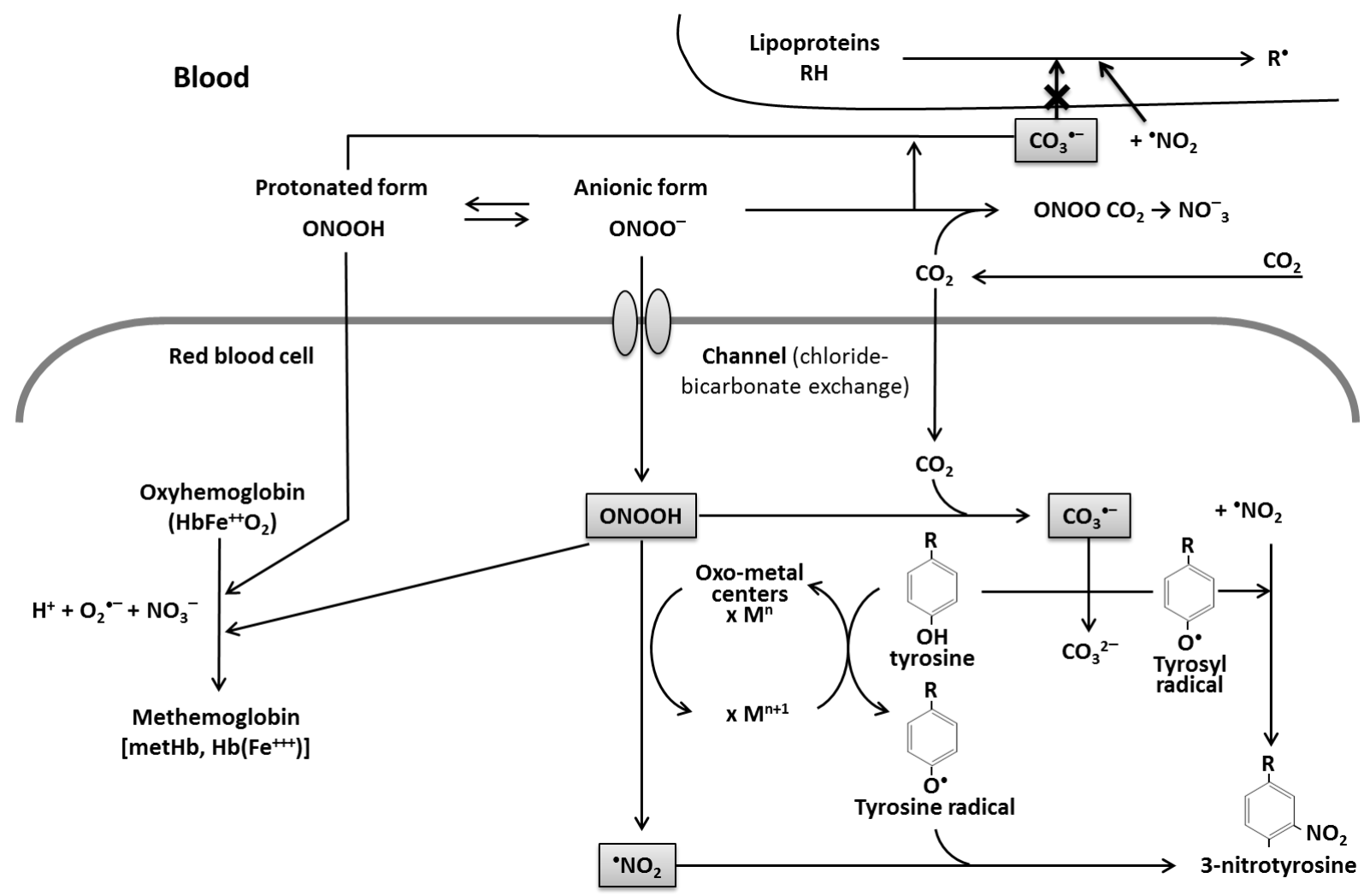

Figure 5.

Schematic representation of sources and consequences of the production of carbonate radical $\left(\mathrm{CO}_{3}{ }^{-}\right)$and peroxynitrite (anionic form: $\mathrm{ONOO}^{-}$) in the blood and red blood cell. $\mathrm{ONOO}^{-}$can also react with $\mathrm{CO}_{2}$ to form a reactive $\mathrm{CO}_{2}$ adduct of $\mathrm{ONOO}^{-}$: nitrosoperoxycarbonate, $\mathrm{ONOOCO}_{2}$. It decomposes to carbonate radical and nitrogen dioxide $\left({ }^{\bullet} \mathrm{NO}_{2}\right)$. These radicals react with tyrosine to give 3-nitrotyrosine. $\mathrm{ONOO}^{-}$is protonated under physiological conditions generating peroxynitrous acid (ONOOH). Oxyhemoglobin represents a relevant intravascular sink of peroxynitrite and the reaction leads to methemoglobin. 


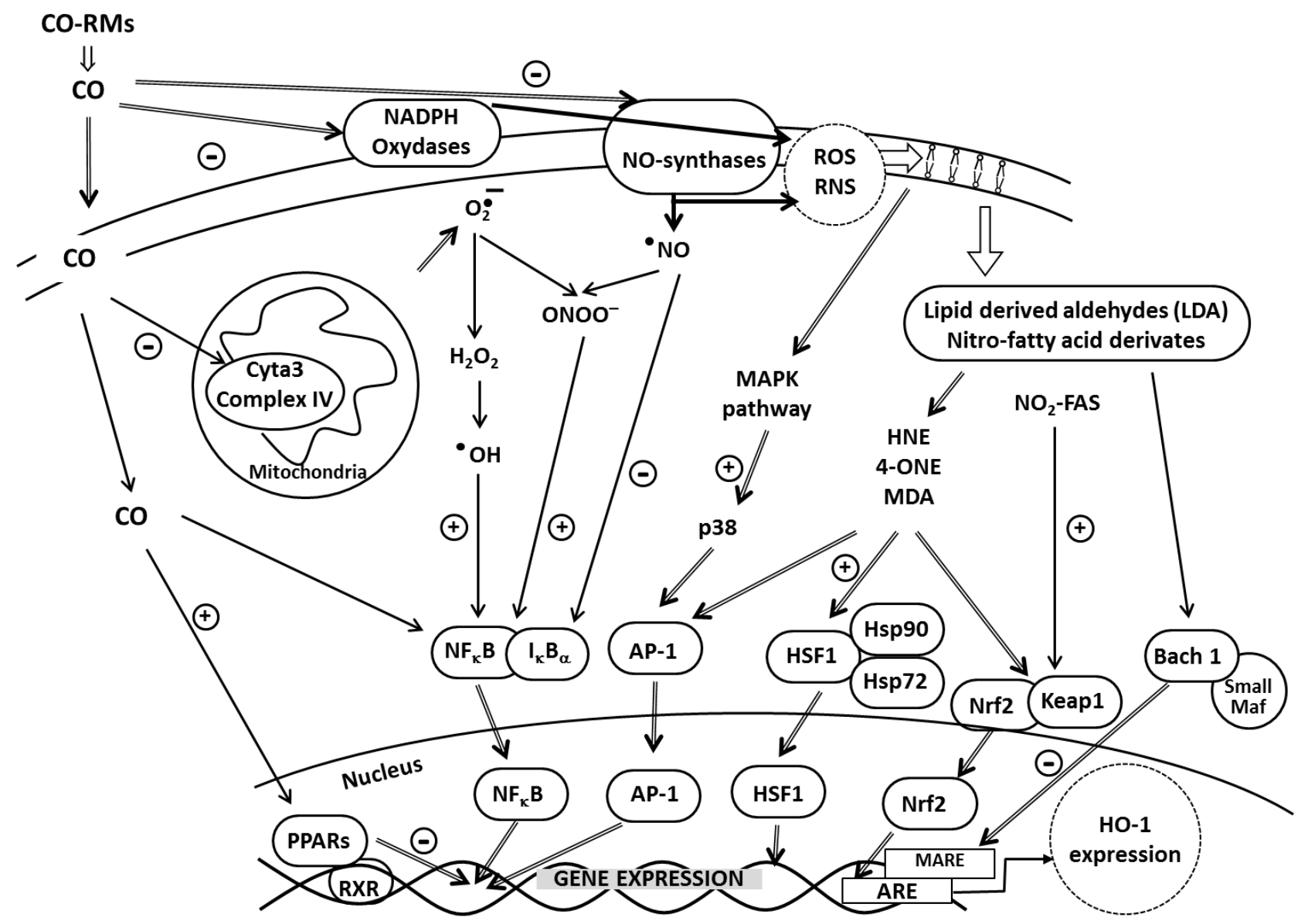

Figure 6

General scheme for the induction of genes expression through the signaling pathways.

Induction of these genes which include antioxidative and heme oxygenase-1 ( $\mathrm{HO}-1)$ genes in adaptive responses that enhance the resistance of cells to environmental stresses mediated by free radicals (Reactive Oxygen Species: ROS andReactive Nitrogen Species: RNS) and electrophilic compounds(Lipid Derived Aldehydes: LDA, Nitro-Fatty acid derivates: $\mathrm{NO}_{2}$-FAS). ROS, RNS and endogenous and exogenous electrophiles/activators (see text for more details)

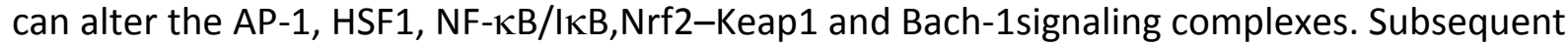
nuclear translocation exits and the induction of antioxidant response element (ARE)-driven genes results in up-regulation of heme oxygenase-1 (HO-1).Bach 1 forms a heterodimer with Maf (Musca domestica antifungal) oncoproteins and binds to the Maf-recognition element (MARE). 
References

Abraham, N. G., Nelson, J. C., Ahmed, T., Konwalinka, G., \& Levere, R. D. (1989). Erythropoietin controls heme metabolic enzymes in normal human bone marrow culture. Exp Hematol, 17, 908-913.

Aizawa, T., Ishizaka, N., Taguchi, J., Nagai, R., Mori, I., Tang, S. S., Ingelfinger, J. R., \& Ohno, M. (2000). Heme oxygenase- 1 is upregulated in the kidney of angiotensin II-induced hypertensive rats : possible role in renoprotection. Hypertension, 35, 800-806.

Akamatsu, Y., Haga, M., Tyagi, S., Yamashita, K., Graca-Souza, A. V., Ollinger, R., Czismadia, E., May, G. A., Ifedigbo, E., Otterbein, L. E., Bach, F. H., \& Soares, M. P. (2004). Heme oxygenase-1derived carbon monoxide protects hearts from transplant associated ischemia reperfusion injury. FASEB J, 18, 771-772.

Al-Assaf, S., Navaratnam, S., Parsons, B. J., \& Phillips, G. O. (2006). Chain scission of hyaluronan by carbonate and dichloride radical anions: potential reactive oxidative species in inflammation? Free Radical Biology \& Medicine, 40, 2018-2027.

Al Ghouleh, I., Khoo, N. K., Knaus, U. G., Griendling, K. K., Touyz, R. M., Thannickal, V. J., Barchowsky, A., Nauseef, W. M., Kelley, E. E., Bauer, P. M., Darley-Usmar, V., Shiva, S., Cifuentes-Pagano, E., Freeman, B. A., Gladwin, M. T., \& Pagano, P. J. (2011). Oxidases and peroxidases in cardiovascular and lung disease: new concepts in reactive oxygen species signaling. Free Radical Biology \& Medicine, 51, 1271-1288.

Althaus, M., Fronius, M., Buchackert, Y., Vadasz, I., Clauss, W. G., Seeger, W., Motterlini, R., \& Morty, R. E. (2009). Carbon monoxide rapidly impairs alveolar fluid clearance by inhibiting epithelial sodium channels. Am J Respir Cell Mol Biol, 41, 639-650.

Amersi, F., Shen, X. D., Anselmo, D., Melinek, J., Iyer, S., Southard, D. J., Katori, M., Volk, H. D., Busuttil, R. W., Buelow, R., \& Kupiec-Weglinski, J. W. (2002). Ex vivo exposure to carbon monoxide prevents hepatic ischemia/reperfusion injury through p38 MAP kinase pathway. Hepatology, 35, 815-823.

Anzai, A., Anzai, T., Nagai, S., Maekawa, Y., Naito, K., Kaneko, H., Sugano, Y., Takahashi, T., Abe, H., Mochizuki, S., Sano, M., Yoshikawa, T., Okada, Y., Koyasu, S., Ogawa, S., \& Fukuda, K. (2012). Regulatory Role of Dendritic Cells in Post-Infarction Healing and Left Ventricular Remodeling. Circulation.

Ashino, T., Yamanaka, R., Yamamoto, M., Shimokawa, H., Sekikawa, K., Iwakura, Y., Shioda, S., Numazawa, S., \& Yoshida, T. (2008). Negative feedback regulation of lipopolysaccharideinduced inducible nitric oxide synthase gene expression by heme oxygenase-1 induction in macrophages. Mol Immunol, 45, 2106-2115.

Augusto, O., Bonini, M. G., Amanso, A. M., Linares, E., Santos, C. C., \& De Menezes, S. L. (2002). Nitrogen dioxide and carbonate radical anion: two emerging radicals in biology. Free Radical Biology \& Medicine, 32, 841-859.

Bagul, A., Hosgood, S. A., Kaushik, M., \& Nicholson, M. L. (2008). Carbon monoxide protects against ischemia-reperfusion injury in an experimental model of controlled nonheartbeating donor kidney. Transplantation, 85, 576-581.

Balla, J., Vercellotti, G. M., Jeney, V., Yachie, A., Varga, Z., Jacob, H. S., Eaton, J. W., \& Balla, G. (2007). Heme, heme oxygenase, and ferritin: how the vascular endothelium survives (and dies) in an iron-rich environment. Antioxid Redox Signal, 9, 2119-2137.

Barbagallo, I., Marrazzo, G., Frigiola, A., Zappala, A., \& Volti, G. L. (2012). Role of Carbon monoxide in vascular diseases. Curr Pharm Biotechnol.

Bauer, I., \& Pannen, B. H. (2009). Bench-to-bedside review: Carbon monoxide--from mitochondrial poisoning to therapeutic use. Crit Care, 13, 220.

Bauer, M., \& Bauer, I. (2002). Heme oxygenase-1: redox regulation and role in the hepatic response to oxidative stress. Antioxid Redox Signal, 4, 749-758. 
Benderitter, M., Hadj-Saad, F., Lhuissier, M., Maupoil, V., Guilland, J. C., \& Rochette, L. (1996). Effects of exhaustive exercise and vitamin B6 deficiency on free radical oxidative process in male trained rats. Free Radical Biology \& Medicine, 21, 541-549.

Berberat, P. O., Katori, M., Kaczmarek, E., Anselmo, D., Lassman, C., Ke, B., Shen, X., Busuttil, R. W., Yamashita, K., Csizmadia, E., Tyagi, S., Otterbein, L. E., Brouard, S., Tobiasch, E., Bach, F. H., Kupiec-Weglinski, J. W., \& Soares, M. P. (2003). Heavy chain ferritin acts as an antiapoptotic gene that protects livers from ischemia reperfusion injury. FASEB J, 17, 1724-1726.

Bergstraesser, C., Hoeger, S., Song, H., Ermantraut, L., Hottenrot, M., Czymai, T., Schmidt, M., Goebeler, M., Ponelies, N., Stich, C., Loesel, R., Molema, G., Seelen, M., van Son, W., Yard, B. A., \& Rafat, N. (2012). Inhibition of VCAM-1 expression in endothelial cells by CORM-3: the role of the ubiquitin-proteasome system, p38, and mitochondrial respiration. Free Radical Biology \& Medicine, 52, 794-802.

Bernuzzi, F., Recalcati, S., Alberghini, A., \& Cairo, G. (2009). Reactive oxygen species-independent apoptosis in doxorubicin-treated H9c2 cardiomyocytes: role for heme oxygenase-1 downmodulation. Chem Biol Interact, 177, 12-20.

Bhargava, P., \& Lee, C. H. (2012). Role and function of macrophages in the metabolic syndrome. Biochemical Journal, 442, 253-262.

Bilban, M., Bach, F. H., Otterbein, S. L., Ifedigbo, E., d'Avila, J. C., Esterbauer, H., Chin, B. Y., Usheva, A., Robson, S. C., Wagner, O., \& Otterbein, L. E. (2006). Carbon monoxide orchestrates a protective response through PPARgamma. Immunity, 24, 601-610.

Bilban, M., Haschemi, A., Wegiel, B., Chin, B. Y., Wagner, O., \& Otterbein, L. E. (2008). Heme oxygenase and carbon monoxide initiate homeostatic signaling. J Mol Med (Berl), 86, 267279.

Brouard, S., Otterbein, L. E., Anrather, J., Tobiasch, E., Bach, F. H., Choi, A. M., \& Soares, M. P. (2000). Carbon monoxide generated by heme oxygenase 1 suppresses endothelial cell apoptosis. J Exp Med, 192, 1015-1026.

Burgess, A., Vanella, L., Bellner, L., Schwartzman, M. L., \& Abraham, N. G. (2012). Epoxyeicosatrienoic acids and heme oxygenase- 1 interaction attenuates diabetes and metabolic syndrome complications. Prostaglandins Other Lipid Mediat, 97, 1-16.

Cairo, G., Recalcati, S., Mantovani, A., \& Locati, M. (2011). Iron trafficking and metabolism in macrophages: contribution to the polarized phenotype. Trends Immunol, 32, 241-247.

Cao, J., Sodhi, K., Puri, N., Monu, S. R., Rezzani, R., \& Abraham, N. G. (2011). High fat diet enhances cardiac abnormalities in SHR rats: Protective role of heme oxygenase-adiponectin axis. Diabetol Metab Syndr, 3, 37.

Chan, K. H., Ng, M. K., \& Stocker, R. (2011). Haem oxygenase-1 and cardiovascular disease: mechanisms and therapeutic potential. Clin Sci (Lond), 120, 493-504.

Chandran, K., McCracken, J., Peterson, F. C., Antholine, W. E., Volkman, B. F., \& Kalyanaraman, B. (2010). Oxidation of histidine residues in copper-zinc superoxide dismutase by bicarbonatestimulated peroxidase and thiol oxidase activities: pulse EPR and NMR studies. Biochemistry, 49, 10616-10622.

Chatterjee, P. K. (2004). Water-soluble carbon monoxide-releasing molecules: helping to elucidate the vascular activity of the 'silent killer'. British Journal of Pharmacology, 142, 391-393.

Chen, B., Guo, L., Fan, C., Bolisetty, S., Joseph, R., Wright, M. M., Agarwal, A., \& George, J. F. (2009). Carbon monoxide rescues heme oxygenase-1-deficient mice from arterial thrombosis in allogeneic aortic transplantation. Am J Pathol, 175, 422-429.

Chen, S. N., \& Hoffman, M. Z. (1973). Rate constants for the reaction of the carbonate radical with compounds of biochemical interest in neutral aqueous solution. Radiat Res, 56, 40-47.

Chlopicki, S., Olszanecki, R., Marcinkiewicz, E., Lomnicka, M., \& Motterlini, R. (2006). Carbon monoxide released by CORM-3 inhibits human platelets by a mechanism independent of soluble guanylate cyclase. Cardiovascular Research, 71, 393-401. 
Choi, B. M., Pae, H. O., Kim, Y. M., \& Chung, H. T. (2003). Nitric oxide-mediated cytoprotection of hepatocytes from glucose deprivation-induced cytotoxicity: involvement of heme oxygenase1. Hepatology, 37, 810-823.

Chung, S. W., Liu, X., Macias, A. A., Baron, R. M., \& Perrella, M. A. (2008). Heme oxygenase-1-derived carbon monoxide enhances the host defense response to microbial sepsis in mice. Journal of Clinical Investigation, 118, 239-247.

Clark, J. E., Naughton, P., Shurey, S., Green, C. J., Johnson, T. R., Mann, B. E., Foresti, R., \& Motterlini, R. (2003). Cardioprotective actions by a water-soluble carbon monoxide-releasing molecule. Circulation Research, 93, e2-8.

Cooper, C. E., \& Brown, G. C. (2008). The inhibition of mitochondrial cytochrome oxidase by the gases carbon monoxide, nitric oxide, hydrogen cyanide and hydrogen sulfide: chemical mechanism and physiological significance. J Bioenerg Biomembr, 40, 533-539.

Coulthard, L. R., White, D. E., Jones, D. L., McDermott, M. F., \& Burchill, S. A. (2009). p38(MAPK): stress responses from molecular mechanisms to therapeutics. Trends Mol Med, 15, 369-379.

Cronje, F. J., Carraway, M. S., Freiberger, J. J., Suliman, H. B., \& Piantadosi, C. A. (2004). Carbon monoxide actuates $\mathrm{O}(2)$-limited heme degradation in the rat brain. Free Radical Biology \& Medicine, 37, 1802-1812.

Dallas, M. L., Boyle, J. P., Milligan, C. J., Sayer, R., Kerrigan, T. L., McKinstry, C., Lu, P., Mankouri, J., Harris, M., Scragg, J. L., Pearson, H. A., \& Peers, C. (2011). Carbon monoxide protects against oxidant-induced apoptosis via inhibition of Kv2.1. FASEB J, 25, 1519-1530.

Dohi, Y., Ikura, T., Hoshikawa, Y., Katoh, Y., Ota, K., Nakanome, A., Muto, A., Omura, S., Ohta, T., Ito, A., Yoshida, M., Noda, T., \& Igarashi, K. (2008). Bach1 inhibits oxidative stress-induced cellular senescence by impeding p53 function on chromatin. Nat Struct Mol Biol, 15, 12461254.

Dong, D. L., Zhang, Y., Lin, D. H., Chen, J., Patschan, S., Goligorsky, M. S., Nasjletti, A., Yang, B. F., \& Wang, W. H. (2007). Carbon monoxide stimulates the Ca2(+)-activated big conductance $\mathrm{k}$ channels in cultured human endothelial cells. Hypertension, 50, 643-651.

Dordelmann, G., Pfeiffer, H., Birkner, A., \& Schatzschneider, U. (2011). Silicium dioxide nanoparticles as carriers for photoactivatable CO-releasing molecules (PhotoCORMs). Inorg Chem, 50, $4362-4367$.

Durante, W. (2010). Targeting heme oxygenase-1 in vascular disease. Curr Drug Targets, 11, 15041516.

Durante, W. (2012). Protective role of heme oxygenase-1 against inflammation in atherosclerosis. Front Biosci, 17, 2372-2388.

Ecarnot-Laubriet, A., Assem, M., Poirson-Bichat, F., Moisant, M., Bernard, C., Lecour, S., Solary, E., Rochette, L., \& Teyssier, J. R. (2002). Stage-dependent activation of cell cycle and apoptosis mechanisms in the right ventricle by pressure overload. Biochim Biophys Acta, 1586, 233242.

Ecarnot-Laubriet, A., De Luca, K., Vandroux, D., Moisant, M., Bernard, C., Assem, M., Rochette, L., \& Teyssier, J. R. (2000). Downregulation and nuclear relocation of MLP during the progression of right ventricular hypertrophy induced by chronic pressure overload. Journal of Molecular \& Cellular Cardiology, 32, 2385-2395.

Fontenay, M., Cathelin, S., Amiot, M., Gyan, E., \& Solary, E. (2006). Mitochondria in hematopoiesis and hematological diseases. Oncogene, 25, 4757-4767.

Foresti, R., \& Motterlini, R. (2010). Interaction of carbon monoxide with transition metals: evolutionary insights into drug target discovery. Curr Drug Targets, 11, 1595-1604.

Fredenburgh, L. E., Perrella, M. A., \& Mitsialis, S. A. (2007). The role of heme oxygenase-1 in pulmonary disease. Am J Respir Cell Mol Biol, 36, 158-165.

Fujita, T., Toda, K., Karimova, A., Yan, S. F., Naka, Y., Yet, S. F., \& Pinsky, D. J. (2001). Paradoxical rescue from ischemic lung injury by inhaled carbon monoxide driven by derepression of fibrinolysis. Nat Med, 7, 598-604. 
Ghibu, S., Delemasure, S., Richard, C., Guilland, J. C., Martin, L., Gambert, S., Rochette, L., \& Vergely, C. (2012). General oxidative stress during doxorubicin-induced cardiotoxicity in rats: Absence of cardioprotection and low antioxidant efficiency of alpha-lipoic acid. Biochimie, 94, 932939.

Ghibu, S., Lauzier, B., Delemasure, S., Amoureux, S., Sicard, P., Vergely, C., Muresan, A., Mogosan, C., \& Rochette, L. (2009). Antioxidant properties of alpha-lipoic acid: effects on red blood membrane permeability and adaptation of isolated rat heart to reversible ischemia. Molecular \& Cellular Biochemistry, 320, 141-148.

Gonzalez, M. A., Yim, M. A., Cheng, S., Moyes, A., Hobbs, A. J., \& Mascharak, P. K. (2012). Manganese carbonyls bearing tripodal polypyridine ligands as photoactive carbon monoxide-releasing molecules. Inorg Chem, 51, 601-608.

Grochot-Przeczek, A., Dulak, J., \& Jozkowicz, A. (2010). Heme oxygenase-1 in neovascularisation: A diabetic perspective. Thromb Haemost, 104, 424-431.

Halliwell, B. (2007a). Free Radicals in Biology and Medicine. (4th Edition ed.). New York: Oxford Biosciences.

Halliwell, B. (2007b). Oxidative stress and cancer: have we moved forward? Biochemical Journal, 401, 1-11.

Hart, J. L. (2011). Role of sulfur-containing gaseous substances in the cardiovascular system. Front Biosci (Elite Ed), 3, 736-749.

Haschemi, A., Chin, B. Y., Jeitler, M., Esterbauer, H., Wagner, O., Bilban, M., \& Otterbein, L. E. (2011). Carbon monoxide induced PPARgamma SUMOylation and UCP2 block inflammatory gene expression in macrophages. PLoS One, 6, e26376.

Heli, H., Mirtorabi, S., \& Karimian, K. (2011). Advances in iron chelation: an update. Expert Opin Ther Pat, 21, 819-856.

Hock, T. D., Liby, K., Wright, M. M., McConnell, S., Schorpp-Kistner, M., Ryan, T. M., \& Agarwal, A. (2007). JunB and JunD regulate human heme oxygenase-1 gene expression in renal epithelial cells. Journal of Biological Chemistry, 282, 6875-6886.

Hoetzel, A., Dolinay, T., Schmidt, R., Choi, A. M., \& Ryter, S. W. (2007). Carbon monoxide in sepsis. Antioxid Redox Signal, 9, 2013-2026.

Hoffman, A., Goldstein, S., Samuni, A., Borman, J. B., \& Schwalb, H. (2003). Effect of nitric oxide and nitroxide SOD-mimic on the recovery of isolated rat heart following ischemia and reperfusion. Biochem Pharmacol, 66, 1279-1286.

Horvath, I., \& Barnes, P. J. (1999). Exhaled monoxides in asymptomatic atopic subjects. Clin Exp Allergy, 29, 1276-1280.

Hosick, P. A., \& Stec, D. E. (2012). Heme oxygenase, a novel target for the treatment of hypertension and obesity? Am J Physiol Regul Integr Comp Physiol, 302, R207-214.

Hultqvist, M., Olsson, L. M., Gelderman, K. A., \& Holmdahl, R. (2009). The protective role of ROS in autoimmune disease. Trends Immunol, 30, 201-208.

Hybertson, B. M., Gao, B., Bose, S. K., \& McCord, J. M. (2011). Oxidative stress in health and disease: the therapeutic potential of Nrf2 activation. Mol Aspects Med, 32, 234-246.

Igarashi, K., \& Sun, J. (2006). The heme-Bach1 pathway in the regulation of oxidative stress response and erythroid differentiation. Antioxid Redox Signal, 8, 107-118.

Ikehara, S. (2010). The future of stem cell transplantation in autoimmune disease. Clin Rev Allergy Immunol, 38, 292-297.

Immenschuh, S., Baumgart-Vogt, E., \& Mueller, S. (2010). Heme oxygenase-1 and iron in liver inflammation: a complex alliance. Curr Drug Targets, 11, 1541-1550.

Inoue, S., Suzuki, M., Nagashima, Y., Suzuki, S., Hashiba, T., Tsuburai, T., Ikehara, K., Matsuse, T., \& Ishigatsubo, Y. (2001). Transfer of heme oxygenase 1 cDNA by a replication-deficient adenovirus enhances interleukin 10 production from alveolar macrophages that attenuates lipopolysaccharide-induced acute lung injury in mice. Hum Gene Ther, 12, 967-979.

Jang, J. H., Lee, T. J., Yang, E. S., Min do, S., Kim, Y. H., Kim, S. H., Choi, Y. H., Park, J. W., Choi, K. S., \& Kwon, T. K. (2010). Compound C sensitizes Caki renal cancer cells to TRAIL-induced apoptosis 
through reactive oxygen species-mediated down-regulation of c-FLIPL and Mcl-1. Exp Cell Res, 316, 2194-2203.

Jay, D., Hitomi, H., \& Griendling, K. K. (2006). Oxidative stress and diabetic cardiovascular complications. Free Radical Biology \& Medicine, 40, 183-192.

Jeong, G. S., Oh, G. S., Pae, H. O., Jeong, S. O., Kim, Y. C., Shin, M. K., Seo, B. Y., Han, S. Y., Lee, H. S., Jeong, J. G., Koh, J. S., \& Chung, H. T. (2006). Comparative effects of curcuminoids on endothelial heme oxygenase-1 expression: ortho-methoxy groups are essential to enhance heme oxygenase activity and protection. Exp Mol Med, 38, 393-400.

Kaizu, T., Ikeda, A., Nakao, A., Tsung, A., Toyokawa, H., Ueki, S., Geller, D. A., \& Murase, N. (2008). Protection of transplant-induced hepatic ischemia/reperfusion injury with carbon monoxide via MEK/ERK1/2 pathway downregulation. Am J Physiol Gastrointest Liver Physiol, 294, G236244.

Kajimura, M., Fukuda, R., Bateman, R. M., Yamamoto, T., \& Suematsu, M. (2010). Interactions of multiple gas-transducing systems: hallmarks and uncertainties of $\mathrm{CO}, \mathrm{NO}$, and $\mathrm{H} 2 \mathrm{~S}$ gas biology. Antioxid Redox Signal, 13, 157-192.

Kajimura, M., Goda, N., \& Suematsu, M. (2002). Organ design for generation and reception of CO: lessons from the liver. Antioxid Redox Signal, 4, 633-637.

Kansanen, E., Jyrkkanen, H. K., \& Levonen, A. L. (2012). Activation of stress signaling pathways by electrophilic oxidized and nitrated lipids. Free Radical Biology \& Medicine, 52, 973-982.

Kanu, A., \& Leffler, C. W. (2007). Carbon monoxide and Ca2+-activated K+ channels in cerebral arteriolar responses to glutamate and hypoxia in newborn pigs. Am J Physiol Heart Circ Physiol, 293, H3193-3200.

Kaspar, J. W., \& Jaiswal, A. K. (2010). Antioxidant-induced phosphorylation of tyrosine 486 leads to rapid nuclear export of Bach1 that allows Nrf2 to bind to the antioxidant response element and activate defensive gene expression. Journal of Biological Chemistry, 285, 153-162.

Kawamoto, A., \& Asahara, T. (2007). Role of progenitor endothelial cells in cardiovascular disease and upcoming therapies. Catheter Cardiovasc Interv, 70, 477-484.

Kemp, K., Morse, R., Sanders, K., Hows, J., \& Donaldson, C. (2011). Alkylating chemotherapeutic agents cyclophosphamide and melphalan cause functional injury to human bone marrowderived mesenchymal stem cells. Ann Hematol, 90, 777-789.

Kennett, E. C., \& Davies, M. J. (2009). Glycosaminoglycans are fragmented by hydroxyl, carbonate, and nitrogen dioxide radicals in a site-selective manner: implications for peroxynitritemediated damage at sites of inflammation. Free Radical Biology \& Medicine, 47, 389-400.

Khan, A. A., \& Quigley, J. G. (2011). Control of intracellular heme levels: heme transporters and heme oxygenases. Biochim Biophys Acta, 1813, 668-682.

Khoo, N. K., \& Freeman, B. A. (2010). Electrophilic nitro-fatty acids: anti-inflammatory mediators in the vascular compartment. Curr Opin Pharmacol, 10, 179-184.

Khoo, N. K., Rudolph, V., Cole, M. P., Golin-Bisello, F., Schopfer, F. J., Woodcock, S. R., Batthyany, C., \& Freeman, B. A. (2010). Activation of vascular endothelial nitric oxide synthase and heme oxygenase-1 expression by electrophilic nitro-fatty acids. Free Radical Biology \& Medicine, 48, 230-239.

Kim, H. P., Ryter, S. W., \& Choi, A. M. (2006). CO as a cellular signaling molecule. Annu Rev Pharmacol Toxicol, 46, 411-449.

Kim, H. P., Wang, X., Nakao, A., Kim, S. I., Murase, N., Choi, M. E., Ryter, S. W., \& Choi, A. M. (2005). Caveolin-1 expression by means of p38beta mitogen-activated protein kinase mediates the antiproliferative effect of carbon monoxide. Proc Natl Acad Sci U S A, 102, 11319-11324.

Kim, Y. M., Pae, H. O., Park, J. E., Lee, Y. C., Woo, J. M., Kim, N. H., Choi, Y. K., Lee, B. S., Kim, S. R., \& Chung, H. T. (2011). Heme oxygenase in the regulation of vascular biology: from molecular mechanisms to therapeutic opportunities. Antioxid Redox Signal, 14, 137-167.

Koliaraki, V., \& Kollias, G. (2011). A new role for myeloid HO-1 in the innate to adaptive crosstalk and immune homeostasis. Adv Exp Med Biol, 780, 101-111. 
Korandji, C., Zeller, M., Guilland, J. C., Collin, B., Lauzier, B., Sicard, P., Duvillard, L., Goirand, F., Moreau, D., Cottin, Y., Rochette, L., \& Vergely, C. (2011). Time course of asymmetric dimethylarginine (ADMA) and oxidative stress in fructose-hypertensive rats: A model related to metabolic syndrome. Atherosclerosis, 214, 310-315.

Korandji, C., Zeller, M., Guilland, J. C., Vergely, C., Sicard, P., Duvillard, L., Gambert, P., Moreau, D., Cottin, Y., \& Rochette, L. (2007). Asymmetric dimethylarginine (ADMA) and hyperhomocysteinemia in patients with acute myocardial infarction. Clin Biochem, 40, 66-72.

Krause, P., Watzig, E., Acil, H., Konig, S., Unthan-Fechner, K., Tsikas, D., \& Probst, I. (2010). Role of carbon monoxide and nitric oxide in adult rat hepatocytes proliferating in vitro: Effects of CAS 1609. Nitric Oxide, 23, 220-226.

Kruger, A. L., Peterson, S. J., Schwartzman, M. L., Fusco, H., McClung, J. A., Weiss, M., Shenouda, S., Goodman, A. I., Goligorsky, M. S., Kappas, A., \& Abraham, N. G. (2006). Up-regulation of heme oxygenase provides vascular protection in an animal model of diabetes through its antioxidant and antiapoptotic effects. J Pharmacol Exp Ther, 319, 1144-1152.

Kyriakis, J. M., \& Avruch, J. (2001). Mammalian mitogen-activated protein kinase signal transduction pathways activated by stress and inflammation. Physiol Rev, 81, 807-869.

Lamon, B. D., Zhang, F. F., Puri, N., Brodsky, S. V., Goligorsky, M. S., \& Nasjletti, A. (2009). Dual pathways of carbon monoxide-mediated vasoregulation: modulation by redox mechanisms. Circulation Research, 105, 775-783.

Lauzier, B., Delemasure, S., Debin, R., Collin, B., Sicard, P., Acar, N., Bretillon, L., Joffre, C., Bron, A., Creuzot-Garcher, C., Vergely, C., \& Rochette, L. (2008). Beneficial effects of myocardial postconditioning are associated with reduced oxidative stress in a senescent mouse model. Transplantation, 85, 1802-1808.

Lauzier, B., Delemasure, S., Pesant, M., Collin, B., Duvillard, L., Vergely, C., Connat, J. L., \& Rochette, L. (2009). A cholesterol-rich diet improves resistance to ischemic insult in mouse hearts but suppresses the beneficial effect of post-conditioning. J Heart Lung Transplant, 28, 821-826.

Lauzier, B., Sicard, P., Bouchot, O., Delemasure, S., Menetrier, F., Moreau, D., Vergely, C., \& Rochette, L. (2007). After four hours of cold ischemia and cardioplegic protocol, the heart can still be rescued with postconditioning. Transplantation, 84, 1474-1482.

Lauzier, B., Sicard, P., Bouchot, O., Delemasure, S., Moreau, D., Vergely, C., \& Rochette, L. (2007). A peroxynitrite decomposition catalyst: FeTPPS confers cardioprotection during reperfusion after cardioplegic arrest in a working isolated rat heart model. Fundam Clin Pharmacol, 21, 173-180.

Lecour, S., Maupoil, V., Siri, O., Tabard, A., \& Rochette, L. (1999). Electron spin resonance detection of nitric oxide generation in major organs from LPS-treated rats. Journal of Cardiovascular Pharmacology, 33, 78-85.

Lecour, S., Maupoil, V., Zeller, M., Laubriet, A., Briot, F., \& Rochette, L. (2001). Levels of nitric oxide in the heart after experimental myocardial ischemia. Journal of Cardiovascular Pharmacology, $37,55-63$.

Lee, B. S., Heo, J., Kim, Y. M., Shim, S. M., Pae, H. O., \& Chung, H. T. (2006). Carbon monoxide mediates heme oxygenase 1 induction via Nrf2 activation in hepatoma cells. Biochem Biophys Res Commun, 343, 965-972.

Lee, S. J., Ryter, S. W., Xu, J., Nakahira, K., Kim, H. P., Choi, A. M., \& Kim, Y. S. (2011). Carbon Monoxide Activates Autophagy via Mitochondrial Reactive Oxygen Species Formation. Am J Respir Cell Mol Biol.

Leffler, C. W., Parfenova, H., \& Jaggar, J. H. (2011). Carbon monoxide as an endogenous vascular modulator. Am J Physiol Heart Circ Physiol, 301, H1-H11.

Li, M., \& Fukagawa, N. K. (2010). Age-related changes in redox signaling and VSMC function. Antioxid Redox Signal, 12, 641-655.

Li, Q., Guo, Y., Ou, Q., Cui, C., Wu, W. J., Tan, W., Zhu, X., Lanceta, L. B., Sanganalmath, S. K., Dawn, B., Shinmura, K., Rokosh, G. D., Wang, S., \& Bolli, R. (2009). Gene transfer of inducible nitric 
oxide synthase affords cardioprotection by upregulating heme oxygenase-1 via a nuclear factor-\{kappa\}B-dependent pathway. Circulation, 120, 1222-1230.

Li, Y., Qi, J., Liu, K., Li, B., Wang, H., \& Jia, J. (2010). Peroxynitrite-induced nitration of cyclooxygenase2 and inducible nitric oxide synthase promotes their binding in diabetic angiopathy. $\mathrm{Mol}$ Med, 16, 335-342.

Lim, I., Gibbons, S. J., Lyford, G. L., Miller, S. M., Strege, P. R., Sarr, M. G., Chatterjee, S., Szurszewski, J. H., Shah, V. H., \& Farrugia, G. (2005). Carbon monoxide activates human intestinal smooth muscle L-type Ca2+ channels through a nitric oxide-dependent mechanism. Am J Physiol Gastrointest Liver Physiol, 288, G7-14.

Lin, H. H., Chen, Y. H., Yet, S. F., \& Chau, L. Y. (2009). After vascular injury, heme oxygenase-1/carbon monoxide enhances re-endothelialization via promoting mobilization of circulating endothelial progenitor cells. J Thromb Haemost, 7, 1401-1408.

Liu, X. M., Peyton, K. J., Shebib, A. R., Wang, H., \& Durante, W. (2011). Compound C stimulates heme oxygenase-1 gene expression via the Nrf2-ARE pathway to preserve human endothelial cell survival. Biochem Pharmacol, 82, 371-379.

Lo lacono, L., Boczkowski, J., Zini, R., Salouage, I., Berdeaux, A., Motterlini, R., \& Morin, D. (2011). A carbon monoxide-releasing molecule (CORM-3) uncouples mitochondrial respiration and modulates the production of reactive oxygen species. Free Radical Biology \& Medicine, 50 , 1556-1564.

Lochhead, P. A., Gilley, R., \& Cook, S. J. (2012). ERK5 and its role in tumour development. Biochem Soc Trans, 40, 251-256.

Lu, S. C. (2009). Regulation of glutathione synthesis. Mol Aspects Med, 30, 42-59.

Lu, S. P., Lin Feng, M. H., Huang, H. L., Huang, Y. C., Tsou, W. I., \& Lai, M. Z. (2007). Reactive oxygen species promote raft formation in T lymphocytes. Free Radical Biology \& Medicine, 42, 936944.

MacLeod, A. K., McMahon, M., Plummer, S. M., Higgins, L. G., Penning, T. M., Igarashi, K., \& Hayes, J. D. (2009). Characterization of the cancer chemopreventive NRF2-dependent gene battery in human keratinocytes: demonstration that the KEAP1-NRF2 pathway, and not the BACH1NRF2 pathway, controls cytoprotection against electrophiles as well as redox-cycling compounds. Carcinogenesis, 30, 1571-1580.

Maicas, N., Ferrandiz, M. L., Devesa, I., Motterlini, R., Koenders, M. I., van den Berg, W. B., \& Alcaraz, M. J. (2010). The CO-releasing molecule CORM-3 protects against articular degradation in the K/BxN serum transfer arthritis model. European Journal of Pharmacology, 634, 184-191.

Mann, B. E., \& Motterlini, R. (2007). CO and NO in medicine. Chem Commun (Camb), 4197-4208.

Meli, R., Nauser, T., Latal, P., \& Koppenol, W. H. (2002). Reaction of peroxynitrite with carbon dioxide: intermediates and determination of the yield of $\mathrm{CO}^{*}$ - and $\mathrm{NO}^{*}$. J Biol Inorg Chem, 7, 31-36.

Min, K. J., Lee, J. T., Joe, E. H., \& Kwon, T. K. (2011). An IkappaBalpha phosphorylation inhibitor induces heme oxygenase-1(HO-1) expression through the activation of reactive oxygen species (ROS)-Nrf2-ARE signaling and ROS-PI3K/Akt signaling in an NF-kappaB-independent mechanism. Cell Signal, 23, 1505-1513.

Miyazaki, T., Kirino, Y., Takeno, M., Samukawa, S., Hama, M., Tanaka, M., Yamaji, S., Ueda, A., Tomita, N., Fujita, H., \& Ishigatsubo, Y. (2010). Expression of heme oxygenase-1 in human leukemic cells and its regulation by transcriptional repressor Bach1. Cancer Sci, 101, 1409-1416.

Morse, D., Lin, L., Choi, A. M., \& Ryter, S. W. (2009). Heme oxygenase-1, a critical arbitrator of cell death pathways in lung injury and disease. Free Radical Biology \& Medicine, 47, 1-12.

Motterlini, R. (2007). Carbon monoxide-releasing molecules (CO-RMs): vasodilatory, anti-ischaemic and anti-inflammatory activities. Biochem Soc Trans, 35, 1142-1146.

Motterlini, R., Mann, B. E., Johnson, T. R., Clark, J. E., Foresti, R., \& Green, C. J. (2003). Bioactivity and pharmacological actions of carbon monoxide-releasing molecules. Curr Pharm Des, 9, 25252539. 
Motterlini, R., \& Otterbein, L. E. (2010). The therapeutic potential of carbon monoxide. Nat Rev Drug Discov, 9, 728-743.

Motterlini, R., Sawle, P., Hammad, J., Bains, S., Alberto, R., Foresti, R., \& Green, C. J. (2005). CORMA1: a new pharmacologically active carbon monoxide-releasing molecule. FASEB J, 19, 284286.

Mustafa, M. R., \& Johns, E. J. (2001). The role of haem oxygenase in renal vascular reactivity in normotensive and hypertensive rats. J Hypertens, 19, 1105-1111.

Nakashima, I., Kato, M., Akhand, A. A., Suzuki, H., Takeda, K., Hossain, K., \& Kawamoto, Y. (2002). Redox-linked signal transduction pathways for protein tyrosine kinase activation. Antioxid Redox Signal, 4, 517-531.

Ndisang, J. F., Tabien, H. E., \& Wang, R. (2004). Carbon monoxide and hypertension. J Hypertens, 22, 1057-1074.

Ogawa, K., Sun, J., Taketani, S., Nakajima, O., Nishitani, C., Sassa, S., Hayashi, N., Yamamoto, M., Shibahara, S., Fujita, H., \& Igarashi, K. (2001). Heme mediates derepression of Maf recognition element through direct binding to transcription repressor Bach1. EMBO J, 20, 2835-2843.

Ogborne, R. M., Rushworth, S. A., \& O'Connell, M. A. (2005). Alpha-lipoic acid-induced heme oxygenase-1 expression is mediated by nuclear factor erythroid 2-related factor 2 and p38 mitogen-activated protein kinase in human monocytic cells. Arterioscler Thromb Vasc Biol, 25, 2100-2105.

Ohara, Y., Ohara, T., Ohrui, T., Morikawa, T., Asamura, T., Sasaki, H., \& Arai, H. (2012). Exhaled carbon monoxide levels in preschool-age children with episodic asthma. Pediatr Int, 54, 227-232.

Ollinger, R., \& Pratschke, J. (2010). Role of heme oxygenase-1 in transplantation. Transpl Int, 23, 1071-1081.

Opie, L. (1989). Reperfusion injury and its pharmacological modification. Circulation, 80, 1049-1062.

Otterbein, L. E., Bach, F. H., Alam, J., Soares, M., Tao Lu, H., Wysk, M., Davis, R. J., Flavell, R. A., \& Choi, A. M. (2000). Carbon monoxide has anti-inflammatory effects involving the mitogenactivated protein kinase pathway. Nat Med, 6, 422-428.

Otterbein, L. E., Otterbein, S. L., Ifedigbo, E., Liu, F., Morse, D. E., Fearns, C., Ulevitch, R. J., Knickelbein, R., Flavell, R. A., \& Choi, A. M. (2003). MKK3 mitogen-activated protein kinase pathway mediates carbon monoxide-induced protection against oxidant-induced lung injury. Am J Pathol, 163, 2555-2563.

Ozaki, K. S., Marques, G. M., Nogueira, E., Feitoza, R. Q., Cenedeze, M. A., Franco, M. F., Mazzali, M., Soares, M. P., Pacheco-Silva, A., \& Camara, N. O. (2008). Improved renal function after kidney transplantation is associated with heme oxygenase-1 polymorphism. Clin Transplant, 22, 609616.

Pacher, P., Beckman, J. S., \& Liaudet, L. (2007). Nitric oxide and peroxynitrite in health and disease. Physiol Rev, 87, 315-424.

Pae, H. O., Oh, G. S., Choi, B. M., Chae, S. C., Kim, Y. M., Chung, K. R., \& Chung, H. T. (2004). Carbon monoxide produced by heme oxygenase-1 suppresses $T$ cell proliferation via inhibition of IL-2 production. J Immunol, 172, 4744-4751.

Paine, A., Eiz-Vesper, B., Blasczyk, R., \& Immenschuh, S. (2010). Signaling to heme oxygenase-1 and its anti-inflammatory therapeutic potential. Biochem Pharmacol, 80, 1895-1903.

Patel, H. H., \& Insel, P. A. (2009). Lipid rafts and caveolae and their role in compartmentation of redox signaling. Antioxid Redox Signal, 11, 1357-1372.

Peers, C. (2011). Ion channels as target effectors for carbon monoxide. Exp Physiol, 96, 836-839.

Peers, C., \& Steele, D. S. (2012). Carbon monoxide: a vital signalling molecule and potent toxin in the myocardium. Journal of Molecular \& Cellular Cardiology, 52, 359-365.

Peng, J., Lu, R., Ye, F., Deng, H. W., \& Li, Y. J. (2002). The heme oxygenase-1 pathway is involved in calcitonin gene-related peptide-mediated delayed cardioprotection induced by monophosphoryl lipid A in rats. Regul Pept, 103, 1-7.

Piantadosi, C. A. (2002). Biological chemistry of carbon monoxide. Antioxid Redox Signal, 4, 259-270. 
Piantadosi, C. A. (2008). Carbon monoxide, reactive oxygen signaling, and oxidative stress. Free Radical Biology \& Medicine, 45, 562-569.

Piantadosi, C. A., Tatro, L., \& Zhang, J. (1995). Hydroxyl radical production in the brain after CO hypoxia in rats. Free Radical Biology \& Medicine, 18, 603-609.

Pizarro, M. D., Rodriguez, J. V., Mamprin, M. E., Fuller, B. J., Mann, B. E., Motterlini, R., \& Guibert, E. E. (2009). Protective effects of a carbon monoxide-releasing molecule (CORM-3) during hepatic cold preservation. Cryobiology, 58, 248-255.

Prockop, L. D., \& Chichkova, R. I. (2007). Carbon monoxide intoxication: an updated review. J Neurol Sci, 262, 122-130.

Puntarulo, S. (2005). Iron, oxidative stress and human health. Mol Aspects Med, 26, 299-312.

Radhakrishnan, N., Yadav, S. P., Sachdeva, A., Pruthi, P. K., Sawhney, S., Piplani, T., Wada, T., \& Yachie, A. (2011). Human heme oxygenase-1 deficiency presenting with hemolysis, nephritis, and asplenia. J Pediatr Hematol Oncol, 33, 74-78.

Radi, R., Cassina, A., Hodara, R., Quijano, C., \& Castro, L. (2002). Peroxynitrite reactions and formation in mitochondria. Free Radical Biology \& Medicine, 33, 1451-1464.

Radi, R., Peluffo, G., Alvarez, M. N., Naviliat, M., \& Cayota, A. (2001). Unraveling peroxynitrite formation in biological systems. Free Radical Biology \& Medicine, 30, 463-488.

Ramirez, D. C., Gomez Mejiba, S. E., \& Mason, R. P. (2005). Mechanism of hydrogen peroxide-induced $\mathrm{Cu}, \mathrm{Zn}$-superoxide dismutase-centered radical formation as explored by immuno-spin trapping: the role of copper- and carbonate radical anion-mediated oxidations. Free Radical Biology \& Medicine, 38, 201-214.

Raval, C. M., \& Lee, P. J. (2010). Heme oxygenase-1 in lung disease. Curr Drug Targets, 11, 1532-1540.

Reyes, B. M., Danese, S., Sans, M., Fiocchi, C., \& Levine, A. D. (2005). Redox equilibrium in mucosal T cells tunes the intestinal TCR signaling threshold. J Immunol, 175, 2158-2166.

Rhodes, M. A., Carraway, M. S., Piantadosi, C. A., Reynolds, C. M., Cherry, A. D., Wester, T. E., Natoli, M. J., Massey, E. W., Moon, R. E., \& Suliman, H. B. (2009). Carbon monoxide, skeletal muscle oxidative stress, and mitochondrial biogenesis in humans. Am J Physiol Heart Circ Physiol, 297, H392-399.

Rochette, L., Tatou, E., Maupoil, V., Zeller, M., Cottin, Y., Jazayeri, S., Brenot, R., Girard, C., David, M., \& Vergely, C. (2011). Atrial and vascular oxidative stress in patients with heart failure. Cell Physiol Biochem, 27, 497-502.

Rochette, L., \& Vergely, C. (2008a). Forgotten radicals in biology. International Journal of Biomedical Sciences, 4.

Rochette, L., \& Vergely, C. (2008b). Le sulfure d'hydrogène $\left(\mathrm{H}_{2} \mathrm{~S}\right)$, un gaz endogène a l'odeur d'oeuf pourri, pourrait être un régulateur des fonctions cardiovasculaires. Annales de Cardiologie et d'Angéiologie, 57, 136-138.

Rund, D., \& Rachmilewitz, E. (2000). New trends in the treatment of beta-thalassemia. Crit Rev Oncol Hematol, 33, 105-118.

Ryter, S. W., Alam, J., \& Choi, A. M. (2006). Heme oxygenase-1/carbon monoxide: from basic science to therapeutic applications. Physiol Rev, 86, 583-650.

Ryter, S. W., \& Choi, A. M. (2010). Heme oxygenase-1/carbon monoxide: novel therapeutic strategies in critical care medicine. Curr Drug Targets, 11, 1485-1494.

Ryter, S. W., \& Otterbein, L. E. (2004). Carbon monoxide in biology and medicine. Bioessays, 26, 270280.

Santos-Silva, T., Mukhopadhyay, A., Seixas, J. D., Bernardes, G. J., Romao, C. C., \& Romao, M. J. (2011). CORM-3 reactivity toward proteins: the crystal structure of a Ru(II) dicarbonyllysozyme complex. J Am Chem Soc, 133, 1192-1195.

Sato, K., Balla, J., Otterbein, L., Smith, R. N., Brouard, S., Lin, Y., Csizmadia, E., Sevigny, J., Robson, S. C., Vercellotti, G., Choi, A. M., Bach, F. H., \& Soares, M. P. (2001). Carbon monoxide generated by heme oxygenase-1 suppresses the rejection of mouse-to-rat cardiac transplants. J Immunol, 166, 4185-4194. 
Sawle, P., Foresti, R., Mann, B. E., Johnson, T. R., Green, C. J., \& Motterlini, R. (2005). Carbon monoxide-releasing molecules (CO-RMs) attenuate the inflammatory response elicited by lipopolysaccharide in RAW264.7 murine macrophages. British Journal of Pharmacology, 145, 800-810.

Scalera, F., Martens-Lobenhoffer, J., Tager, M., Bukowska, A., Lendeckel, U., \& Bode-Boger, S. M. (2006). Effect of L-arginine on asymmetric dimethylarginine (ADMA) or homocysteineaccelerated endothelial cell aging. Biochem Biophys Res Commun, 345, 1075-1082.

Scapagnini, G., Foresti, R., Calabrese, V., Giuffrida Stella, A. M., Green, C. J., \& Motterlini, R. (2002). Caffeic acid phenethyl ester and curcumin: a novel class of heme oxygenase-1 inducers. $\mathrm{Mol}$ Pharmacol, 61, 554-561.

Schmidt, R., Tritschler, E., Hoetzel, A., Loop, T., Humar, M., Halverscheid, L., Geiger, K. K., \& Pannen, B. H. (2007). Heme oxygenase-1 induction by the clinically used anesthetic isoflurane protects rat livers from ischemia/reperfusion injury. Ann Surg, 245, 931-942.

Schuett, H., Eipel, C., Maletzki, C., Menger, M. D., \& Vollmar, B. (2007). NO counterbalances HO-1 overexpression-induced acceleration of hepatocyte proliferation in mice. Lab Invest, 87, 602 612.

Shintani, T., Iwabuchi, T., Soga, T., Kato, Y., Yamamoto, T., Takano, N., Hishiki, T., Ueno, Y., Ikeda, S., Sakuragawa, T., Ishikawa, K., Goda, N., Kitagawa, Y., Kajimura, M., Matsumoto, K., \& Suematsu, M. (2009). Cystathionine beta-synthase as a carbon monoxide-sensitive regulator of bile excretion. Hepatology, 49, 141-150.

Sicard, P., Acar, N., Gregoire, S., Lauzier, B., Bron, A. M., Creuzot-Garcher, C., Bretillon, L., Vergely, C., \& Rochette, L. (2007). Influence of rosuvastatin on the NAD(P)H oxidase activity in the retina and electroretinographic response of spontaneously hypertensive rats. British Journal of Pharmacology, 151, 979-986.

Sicard, P., Delemasure, S., Korandji, C., Segueira-Le Grand, A., Lauzier, B., Guilland, J. C., Duvillard, L., Zeller, M., Cottin, Y., Vergely, C., \& Rochette, L. (2008). Anti-hypertensive effects of Rosuvastatin are associated with decreased inflammation and oxidative stress markers in hypertensive rats. Free Radical Research, 42, 226-236.

Smith, D. J., Ng, H., Kluck, R. M., \& Nagley, P. (2008). The mitochondrial gateway to cell death. IUBMB Life, 60, 383-389.

Soares, M. P., Marguti, I., Cunha, A., \& Larsen, R. (2009). Immunoregulatory effects of HO-1: how does it work? Curr Opin Pharmacol, 9, 482-489.

Spencer, J. P., Vafeiadou, K., Williams, R. J., \& Vauzour, D. (2012). Neuroinflammation: modulation by flavonoids and mechanisms of action. Mol Aspects Med, 33, 83-97.

Srisook, K., Han, S. S., Choi, H. S., Li, M. H., Ueda, H., Kim, C., \& Cha, Y. N. (2006). CO from enhanced $\mathrm{HO}$ activity or from CORM-2 inhibits both $\mathrm{O} 2$ - and NO production and downregulates $\mathrm{HO}-1$ expression in LPS-stimulated macrophages. Biochem Pharmacol, 71, 307-318.

Sueur, S., Pesant, M., Rochette, L., \& Connat, J. L. (2005). Antiapoptotic effect of calcitonin generelated peptide on oxidative stress-induced injury in $\mathrm{H} 9 \mathrm{c} 2$ cardiomyocytes via the RAMP1/CRLR complex. Journal of Molecular \& Cellular Cardiology, 39, 955-963.

Surmeli, N. B., Litterman, N. K., Miller, A. F., \& Groves, J. T. (2010). Peroxynitrite Mediates Active Site Tyrosine Nitration in Manganese Superoxide Dismutase. Evidence of a Role for the Carbonate Radical Anion. J Am Chem Soc.

Taille, C., El-Benna, J., Lanone, S., Boczkowski, J., \& Motterlini, R. (2005). Mitochondrial respiratory chain and NAD(P)H oxidase are targets for the antiproliferative effect of carbon monoxide in human airway smooth muscle. Journal of Biological Chemistry, 280, 25350-25360.

Thom, S. R., Fisher, D., Xu, Y. A., Garner, S., \& Ischiropoulos, H. (1999). Role of nitric oxide-derived oxidants in vascular injury from carbon monoxide in the rat. American Journal of Physiology, 276, H984-992.

Thom, S. R., Fisher, D., Xu, Y. A., Notarfrancesco, K., \& Ischiropoulos, H. (2000). Adaptive responses and apoptosis in endothelial cells exposed to carbon monoxide. Proc Natl Acad Sci U S A, 97, 1305-1310. 
Tzima, S., Victoratos, P., Kranidioti, K., Alexiou, M., \& Kollias, G. (2009). Myeloid heme oxygenase-1 regulates innate immunity and autoimmunity by modulating IFN-beta production. J Exp Med, 206, 1167-1179.

Varadi, J., Lekli, I., Juhasz, B., Bacskay, I., Szabo, G., Gesztelyi, R., Szendrei, L., Varga, E., Bak, I., Foresti, R., Motterlini, R., \& Tosaki, A. (2007). Beneficial effects of carbon monoxide-releasing molecules on post-ischemic myocardial recovery. Life Sci, 80, 1619-1626.

Vergely, C., Maupoil, V., Clermont, G., Bril, A., \& Rochette, L. (2003). Identification and quantification of free radicals during myocardial ischemia and reperfusion using electron paramagnetic resonance spectroscopy. Archives of Biochemistry \& Biophysics, 420, 209-216.

Vergely, C., Perrin-Sarrado, C., Clermont, G., \& Rochette, L. (2002). Postischemic recovery and oxidative stress are independent of nitric oxide synthases modulation in isolated rat heart. Journal of Pharmacology \& Experimental Therapeutics, 303, 149-157.

Vergely, C., Renard, C., Moreau, D., Roubaud, V., Tuccio, B., \& Rochette, L. (2003). Effect of two new PBN-derived phosphorylated nitrones against postischaemic ventricular arrhythmias. Fundamental \& Clinical Pharmacology, 17, 433-442.

Wang, G., Hamid, T., Keith, R. J., Zhou, G., Partridge, C. R., Xiang, X., Kingery, J. R., Lewis, R. K., Li, Q., Rokosh, D. G., Ford, R., Spinale, F. G., Riggs, D. W., Srivastava, S., Bhatnagar, A., Bolli, R., \& Prabhu, S. D. (2010). Cardioprotective and antiapoptotic effects of heme oxygenase-1 in the failing heart. Circulation, 121, 1912-1925.

Wang, L. J., Lee, T. S., Lee, F. Y., Pai, R. C., \& Chau, L. Y. (1998). Expression of heme oxygenase-1 in atherosclerotic lesions. Am J Pathol, 152, 711-720.

Wang, R. (2002). Two's company, three's a crowd: can H2S be the third endogenous gaseous transmitter? FASEB J, 16, 1792-1798.

Wang, X., Wang, Y., Kim, H. P., Nakahira, K., Ryter, S. W., \& Choi, A. M. (2007). Carbon monoxide protects against hyperoxia-induced endothelial cell apoptosis by inhibiting reactive oxygen species formation. Journal of Biological Chemistry, 282, 1718-1726.

Wang, X. M., Kim, H. P., Nakahira, K., Ryter, S. W., \& Choi, A. M. (2009). The heme oxygenase1 /carbon monoxide pathway suppresses TLR4 signaling by regulating the interaction of TLR4 with caveolin-1.J Immunol, 182, 3809-3818.

Watari, Y., Yamamoto, Y., Brydun, A., Ishida, T., Mito, S., Yoshizumi, M., Igarashi, K., Chayama, K., Ohshima, T., \& Ozono, R. (2008). Ablation of the bach1 gene leads to the suppression of atherosclerosis in bach1 and apolipoprotein E double knockout mice. Hypertens Res, 31, 783792.

Watts, R. N., Ponka, P., \& Richardson, D. R. (2003). Effects of nitrogen monoxide and carbon monoxide on molecular and cellular iron metabolism: mirror-image effector molecules that target iron. Biochemical Journal, 369, 429-440.

Wegiel, B., Gallo, D. J., Raman, K. G., Karlsson, J. M., Ozanich, B., Chin, B. Y., Tzeng, E., Ahmad, S., Ahmed, A., Baty, C. J., \& Otterbein, L. E. (2010). Nitric oxide-dependent bone marrow progenitor mobilization by carbon monoxide enhances endothelial repair after vascular injury. Circulation, 121, 537-548.

Whiteman, M., \& Moore, P. K. (2009). Hydrogen sulfide and the vasculature: a novel vasculoprotective entity and regulator of nitric oxide bioavailability? J Cell Mol Med, 13, 488507.

Wilkinson, W. J., \& Kemp, P. J. (2011). Carbon monoxide: an emerging regulator of ion channels. J Physiol, 589, 3055-3062.

Willis, D., Moore, A. R., Frederick, R., \& Willoughby, D. A. (1996). Heme oxygenase: a novel target for the modulation of the inflammatory response. Nat Med, 2, 87-90.

Woo, C. H., \& Abe, J. (2010). SUMO--a post-translational modification with therapeutic potential? Curr Opin Pharmacol, 10, 146-155.

Woo, C. H., Massett, M. P., Shishido, T., Itoh, S., Ding, B., McClain, C., Che, W., Vulapalli, S. R., Yan, C., \& Abe, J. (2006). ERK5 activation inhibits inflammatory responses via peroxisome 
proliferator-activated receptor delta (PPARdelta) stimulation. Journal of Biological Chemistry, 281, 32164-32174.

Wortzel, I., \& Seger, R. (2011). The ERK Cascade: Distinct Functions within Various Subcellular Organelles. Genes Cancer, 2, 195-209.

Wright, M. M., Kim, J., Hock, T. D., Leitinger, N., Freeman, B. A., \& Agarwal, A. (2009). Human haem oxygenase-1 induction by nitro-linoleic acid is mediated by CAMP, AP-1 and E-box response element interactions. Biochemical Journal, 422, 353-361.

Wright, M. M., Schopfer, F. J., Baker, P. R., Vidyasagar, V., Powell, P., Chumley, P., Iles, K. E., Freeman, B. A., \& Agarwal, A. (2006). Fatty acid transduction of nitric oxide signaling: nitrolinoleic acid potently activates endothelial heme oxygenase 1 expression. Proc Natl Acad Sci U S A, 103, 4299-4304.

Wu, B. J., Midwinter, R. G., Cassano, C., Beck, K., Wang, Y., Changsiri, D., Gamble, J. R., \& Stocker, R. (2009). Heme oxygenase-1 increases endothelial progenitor cells. Arterioscler Thromb Vasc Biol, 29, 1537-1542.

Wu, L., Cao, K., Lu, Y., \& Wang, R. (2002). Different mechanisms underlying the stimulation of K(Ca) channels by nitric oxide and carbon monoxide. Journal of Clinical Investigation, 110, 691-700.

Wu, L., \& Wang, R. (2005). Carbon monoxide: endogenous production, physiological functions, and pharmacological applications. Pharmacological Reviews, 57, 585-630.

Wu, M. L., Ho, Y. C., Lin, C. Y., \& Yet, S. F. (2011). Heme oxygenase-1 in inflammation and cardiovascular disease. Am J Cardiovasc Dis, 1, 150-158.

Wu, M. L., Ho, Y. C., \& Yet, S. F. (2011). A central role of heme oxygenase-1 in cardiovascular protection. Antioxid Redox Signal, 15, 1835-1846.

Yamashita, K., Ollinger, R., McDaid, J., Sakahama, H., Wang, H., Tyagi, S., Csizmadia, E., Smith, N. R., Soares, M. P., \& Bach, F. H. (2006). Heme oxygenase-1 is essential for and promotes tolerance to transplanted organs. FASEB J, 20, 776-778.

Yang, L., Quan, S., Nasjletti, A., Laniado-Schwartzman, M., \& Abraham, N. G. (2004). Heme oxygenase-1 gene expression modulates angiotensin II-induced increase in blood pressure. Hypertension, 43, 1221-1226.

Ye, F., Deng, P. Y., Li, D., Luo, D., Li, N. S., Deng, S., Deng, H. W., \& Li, Y. J. (2007). Involvement of endothelial cell-derived CGRP in heat stress-induced protection of endothelial function. Vascul Pharmacol, 46, 238-246.

Young, L. J., \& Caughey, W. S. (1986). Oxygenation of carbon monoxide by bovine heart cytochrome c oxidase. Biochemistry, 25, 152-161.

Zeller, M., Korandji, C., Guilland, J. C., Sicard, P., Vergely, C., Lorgis, L., Beer, J. C., Duvillard, L., Lagrost, A. C., Moreau, D., Gambert, P., Cottin, Y., \& Rochette, L. (2008). Impact of Asymmetric Dimethylarginine on Mortality After Acute Myocardial Infarction. Arteriosclerosis Thrombosis \& Vascular Biology, 28, 954-960.

Zhang, H., Andrekopoulos, C., Joseph, J., Crow, J., \& Kalyanaraman, B. (2004). The carbonate radical anion-induced covalent aggregation of human copper, zinc superoxide dismutase, and alphasynuclein: intermediacy of tryptophan- and tyrosine-derived oxidation products. Free Radical Biology \& Medicine, 36, 1355-1365.

Zhang, J., Yao, X., Yu, R., Bai, J., Sun, Y., Huang, M., Adcock, I. M., \& Barnes, P. J. (2010). Exhaled carbon monoxide in asthmatics: a meta-analysis. Respir Res, 11, 50.

Zhang, W. Q., Whitwood, A. C., Fairlamb, I. J., \& Lynam, J. M. (2010). Group 6 carbon monoxidereleasing metal complexes with biologically-compatible leaving groups. Inorg Chem, 49, 8941-8952.

Zhang, X., Shan, P., Alam, J., Davis, R. J., Flavell, R. A., \& Lee, P. J. (2003). Carbon monoxide modulates Fas/Fas ligand, caspases, and Bcl-2 family proteins via the p38alpha mitogen-activated protein kinase pathway during ischemia-reperfusion lung injury. Journal of Biological Chemistry, 278, 22061-22070.

Zhang, X., Shan, P., Alam, J., Fu, X. Y., \& Lee, P. J. (2005). Carbon monoxide differentially modulates STAT1 and STAT3 and inhibits apoptosis via a phosphatidylinositol 3-kinase/Akt and p38 
kinase-dependent STAT3 pathway during anoxia-reoxygenation injury. Journal of Biological Chemistry, 280, 8714-8721.

Zhou, S., Cui, Z., \& Urban, J. P. (2004). Factors influencing the oxygen concentration gradient from the synovial surface of articular cartilage to the cartilage-bone interface: a modeling study. Arthritis Rheum, 50, 3915-3924.

Zhou, Z., Song, R., Fattman, C. L., Greenhill, S., Alber, S., Oury, T. D., Choi, A. M., \& Morse, D. (2005). Carbon monoxide suppresses bleomycin-induced lung fibrosis. Am J Pathol, 166, 27-37.

Ziskoven, C., Jager, M., Kircher, J., Patzer, T., Bloch, W., Brixius, K., \& Krauspe, R. (2011). Physiology and pathophysiology of nitrosative and oxidative stress in osteoarthritic joint destruction. Can J Physiol Pharmacol, 89, 455-466.

Zuckerbraun, B. S., Chin, B. Y., Wegiel, B., Billiar, T. R., Czsimadia, E., Rao, J., Shimoda, L., Ifedigbo, E., Kanno, S., \& Otterbein, L. E. (2006). Carbon monoxide reverses established pulmonary hypertension. J Exp Med, 203, 2109-2119.

Zuckerbraun, B. S., McCloskey, C. A., Gallo, D., Liu, F., Ifedigbo, E., Otterbein, L. E., \& Billiar, T. R. (2005). Carbon monoxide prevents multiple organ injury in a model of hemorrhagic shock and resuscitation. Shock, 23, 527-532. 